\title{
An Essential Role for SHARPIN in the Regulation of Caspase 1 Activity in Sepsis
}

\author{
Madalina-Viviana Nastase, ${ }^{* \dagger}$ Jinyang Zeng-Brouwers, ${ }^{*}$ Helena Frey, ${ }^{*}$ Louise Tzung-Harn Hsieh, ${ }^{*}$ Chiara Poluzzi, ${ }^{*}$ \\ Janet Beckmann, ${ }^{*}$ Nina Schroeder, ${ }^{*}$ Josef Pfeilschifter, ${ }^{*}$ Jaime Lopez-Mosqueda,${ }^{\ddagger}$ Jan Mersmann, ${ }^{\S}$ Fumiyo Ikeda, \\ Renato V. Iozzo, "Ivan Dikic, ${ }^{\ddagger}$ and Liliana Schaefer*
}

\begin{abstract}
From the Pharmacenter Frankfurt/ZAFES,* the Institute of General Pharmacology and Toxicology, the Institute of Biochemistry II, ${ }^{\ddagger}$ and the Department of Anaesthesia ${ }^{\S}$ Intensive Care Medicine and Pain Therapy, University Hospital Frankfurt, Goethe Universität, Frankfurt am Main, Germany; the National Institute for Chemical-Pharmaceutical Research and Development, ${ }^{\dagger}$ Bucharest, Romania; the Institute of Molecular Biotechnology of the Austrian Academy of Sciences, "Vienna, Austria; and the Department of Pathology, Anatomy and Cell Biology," Sidney Kimmel Medical College, Thomas Jefferson University, Philadelphia, Pennsylvania
\end{abstract}

\author{
Accepted for publication \\ December 16, 2015. \\ Address correspondence to \\ Liliana Schaefer, M.D., \\ Pharmacenter Frankfurt/ \\ ZAFES, Institute of General \\ Pharmacology and Toxicology, \\ Haus 74, 3.108a, Theodor- \\ Stern-Kai 7, 60590, Frankfurt \\ am Main, Germany. E-mail: \\ schaefer@med.uni-frankfurt.de.
}

\begin{abstract}
Sepsis is burdened by high mortality due to uncontrolled inflammatory response to pathogens. Increased caspase 1 activation causing maturation of IL1 $\beta / 18$ remains a therapeutic challenge in sepsis. SHARPIN (shank-associated regulator of G-protein signaling homology domain-interacting protein), a component of the LUBAC (linear ubiquitin chain-assembly complex), regulates inflammation, with unknown effects on caspase 1 activation. Mice lacking Casp1, Casp11, or both in a Sharpin-deficient background were generated, exposed to lipopolysaccharide-induced endotoxemia, and injected with caspase 1 inhibitor. We monitored survival, Il1 $1 / 18$, and caspase $1 / 11$ levels in plasma and organs and deciphered mechanisms of SHARPIN-dependent caspase 1 inhibition. A correlation between LUBAC and active caspase 1 was found in blood mononuclear cells from septic patients. SHARPIN bound caspase 1 and disrupted p20/p10 dimer formation, the last step of caspase 1 processing, thereby inhibiting enzyme activation and maturation of IL1 $\beta / 18$ in a LUBAC-independent manner. In septic patients, LUBAC-independent decline in SHARPIN correlated with enhancement of active caspase 1 in circulating mononuclear cells. Septic Sharpin-deficient mice displayed enrichment in mature Il $1 \beta / 18$ and active caspase 1, and shortened survival. Inhibition of caspase 1 reduced levels of Il $1 \beta / 18$ and splenic cell death, and prolonged survival in septic Sharpindeficient mice. Our findings identify SHARPIN as a potent in vivo caspase 1 inhibitor and propose the caspase 1-SHARPIN interaction as a target in sepsis. (Am J Pathol 2016, 186: 1206-1220; http:// dx.doi.org/10.1016/j.ajpath.2015.12.026)
\end{abstract}

Sepsis is a complex systemic inflammatory response to invading pathogens and remains one of the leading causes of death worldwide. ${ }^{1,2}$ Sensing of the initial trigger by innate immune receptors stimulates the $\mathrm{NF}-\kappa \mathrm{B}$ pathway and synthesis of proinflammatory cytokines, including tumor necrosis factor (TNF) and IL1 $\beta$. $^{3}$ Although overexpression of TNF represents an early response, IL1 $\beta$ abounds throughout sepsis. $^{4-7}$ However, clinical trials in septic patients treated with anakinra, an IL1 receptor antagonist, have not been encouraging. ${ }^{8}$ In contrast, combined inhibition of IL1 $\beta$ and IL18 appears to be a more promising strategy. ${ }^{9}$

The active cysteine protease caspase 1 , positioned upstream of IL1 $\beta$ and $I L 18$, is required for proteolytic cleavage and maturation of both cytokine pro-forms and induces an inflammatory type of cell death, pyroptosis. ${ }^{10}$ Therefore, it is conceivable that inhibiting caspase 1 activation, rather than blocking downstream cytokines, could be a potent therapeutic approach in sepsis. Activation of caspase 1, in turn, is triggered by the assembly of multiprotein complexes, the inflammasomes, ${ }^{11}$ and by caspase $11^{12}$ This process ultimately leads to the conversion of pro-caspase 1 into its cleaved active form, a heterotetramer harboring two p20 and two p10 subunits. ${ }^{13}$ The formation of p20/p10 heterotetramer

Supported by the German Research Council [SCHA 1082/6-1, SFB 815, projects A5 (L.S.), A7 (J.P.), and A17 (J.M.); SFB 1039, project B2 (L.S.); and LOEWE program Ub-Net (L.S. and M.-V.N.)].

Disclosures: None declared. 
is the last step in caspase 1 activation independent of the initial trigger. However, the mechanisms of p20/p10 dimer disruption of caspase 1 are not known.

Ubiquitination is a crucial post-translational regulator of the inflammatory response. ${ }^{14}$ The linear ubiquitin chain assembly complex (LUBAC) consists of heme-oxidized iron regulatory protein 2 ligase-1 (HOIL-1L), HOIL-1L-interacting protein (HOIP), and Shank-associated regulator of G-protein signaling homology domain-interacting protein (SHARPIN). ${ }^{15-17}$ In humans, bi-allelic mutations of HOIL (RBCKl) and homozygous missense mutations of HOIP (RNF31) cause autoinflammation, immunodeficiency, and amylopectinosis. ${ }^{18,19}$ Linear ubiquitination and the activation of the proinflammatory pathway NF- $\mathrm{B}$ are impaired in the fibroblasts of these patients. However, monocytes present a proinflammatory phenotype, underlining that LUBAC components might have cell-specific roles. $^{18,19}$ Sharpin $^{\text {cpdm/cpdm }}$-deficient (cpdm, chronic proliferative dermatitis) mice develop a severe phenotype characterized by progressive epidermal hyperplasia, keratinocytic apoptosis, cutaneous and systemic eosinophilic inflammation, hypoplasia of secondary lymphoid organs, and multiorgan inflammation. ${ }^{20-23}$ Ablation of Tnf, ${ }^{16}$ Tnf receptor 1 , Tnf receptor superfamily member $1 \mathrm{~A}-$ associated via death domain, or Fas-associated protein with death domain rescue the skin phenotype in $C p d m$ mice. ${ }^{24,25}$ However, it is not wellunderstood how SHARPIN deficiency causes inflammation in Cpdm mice. ${ }^{15-17}$

Here we describe a novel regulatory mechanism of caspase 1 activity in sepsis triggered by binding of SHARPIN to p20/ p10 subunits of caspase 1, resulting in dimer disruption. Importantly, we show relevance of these findings to sepsis in humans and lipopolysaccharide (LPS)-induced endotoxemia in mice. Moreover, we provide proof-of-concept for the beneficial effects of caspase 1 inhibition in LPS-induced endotoxemia and report a new molecular mechanism underlying the multiorgan inflammatory phenotype in Cpdm mice.

\section{Materials and Methods}

\section{Study Approval}

All animal experiments were performed in accordance with the German Animal Protection Act and were approved by the Ethics Review Committee for Laboratory Animals, District Government of Darmstadt, Germany. The clinical study (number 367/12) was approved by the ethics committee at Goethe University (Frankfurt am Main, Germany) in accordance with the Declaration of Helsinki. All patients who participated in the study provided written informed consent.

\section{Mice}

C57BL/6 mice were bought from Charles River Laboratories (Wilmington, MA). Homozygous and heterozygous $C p d m$ and Cpdm wild-type (WT) mice were from the C57BL/KaLawRij colony and were raised in the specific pathogen-free breeding facility at the Goethe University animal facility.

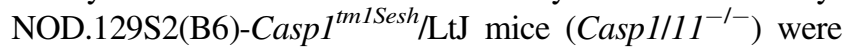
bought from Jackson ImmunoResearch Laboratories (Suffolk, UK). Casp111 ${ }^{-1-}$, Casp1/11 double knockout, and Casp $^{-1-} / 11^{\mathrm{Tg}}$ mice (a gift from Drs. Vishva M. Dixit and Nobuhiko Kayagaki), from C57BL/6 background, have been previously described. ${ }^{12}$ As the caspase 1 and caspase 11 genes are adjacent in the mouse genome, $\operatorname{Casp}^{-1-} / 11^{\mathrm{Tg}}$ mice were generated by transgenic overexpression of caspase 11 in a Casp 1/11 double-knockout background. ${ }^{12}$ CpdmCasp $1 /$ $11^{-1-}, C p d m ; C_{C a s p 11^{-1-}}$, and Cpdm;Casp1 ${ }^{-1-} / 11^{\mathrm{Tg}}$ were obtained by intercrossing (see Mouse Strain Generation and Genotyping). All mice were housed in a pathogen-free facility.

\section{Mouse Strain Generation and Genotyping}

Cpdm;Casp $1 / 11^{-1-}$ mice were generated by intercrossing of heterozygous $C p d m$ mice with Casp $1 / 11^{-/-}$mice and were then back-crossed into the C57BL/6 background. The genotyping of the $C p d m ; C a s p 1 / 11^{-1-}$ mice for the Cpdm mutation was made at Varionostics GmbH (Ulm, Germany). The genotype of the resulting mice was identified by PCR using genomic DNA purified from tail and the following primers for the Casp $1^{\text {tm ISesh }}$ allele: oIMR3769: forward, 5'-GAAGAGATGTTACAGAAGCC-3' (common); oIMR3 770: reverse, 5'-CATGCCTGAATAATGATCACC-3' (WT); and oIMR3771: reverse, 5'-GCGCCTCCCCTACCCGG-3' (mutant). The resulting band size was $600 \mathrm{bp}$ for both WT and mutants. Due to the fact that caspase 1 and caspase 11 are adjacent in the mouse genome and are separated by approximately $1500 \mathrm{bp}$, the presence or absence of the caspase 1 gene implies the same for caspase $11 .{ }^{12}$

Cpdm;Casp $11^{-1-}$ mice were generated by intercrossing of heterozygous $C p d m$ mice with Casp11 $1^{-/-}$mice. The genotyping for the caspase 11 gene was performed by PCR using genomic DNA isolated from tail and the following primers: A: forward, 5'-TGAAATGCATGTACTGAGAGCAAGG-3'; B: reverse, 5'-CAATTGACTTGGGGATTCTGG-3'; and C: forward, 5'-GTCAGAGATGAAAGACTTTGCTGC-3', yielding a 475-bp WT DNA fragment (by using $\mathrm{B}$ and $\mathrm{C}$ primers) and a 337-bp mutant DNA fragment (by using $\mathrm{A}$ and $\mathrm{B}$ primers). ${ }^{12}$

Cpdm;Casp1 ${ }^{-1-} / 11^{\mathrm{Tg}}$ mice were generated by intercrossing of Cpdm;Casp $1 / 11^{-1-}$ mice with Casp $^{-1-} / 11^{\mathrm{Tg}}$ mice. Generation of Caspl $^{-1-}$ Caspl1 $^{\mathrm{Tg}}$ mice was described previously. ${ }^{12}$ The presence of caspase 11 gene was identified by PCR using genomic DNA isolated from tail and the following primers: casp 11, forward, 5'-CTGCAUGCCTAGCTGCATT-3', reverse, 5'-GGGTACCTGAGGATGAAGGA- $3^{\prime}$. A band of $411 \mathrm{bp}$ was predicted. As an endogenous control, an additional PCR was performed by using the following primers: TCRD1: reverse, 5'-GTCGTCAGTCGAGTGCACAGTTT-3'; and TCRD2: forward, 5'-CAAATGTTGCTTGTCTGGTG- $3^{\prime}$. A band of 211 bp resulted. The genotyping for the Cpdm mutation was performed at 
Varionostics GmbH. All primers were bought from SigmaAldrich (Hamburg, Germany). The PCR reactions were performed by using a Primus 96 Plus Thermal Cycler (MWGBiotech AG, Eurofins Genomics, Ebersberg, Germany).

The genomic DNA was isolated from the tail by using the High Pure PCR Template Preparation Kit (Roche Diagnostics, Mannheim, Germany) and the PCR reaction for caspase 11 genotyping was performed by using a HotStarTaq DNA Polymerase Kit (Qiagen, Hilden, Germany) from the $10 \times$ Hotstart PCR-Master Mix B2 (Bio\&SELL, Feucht, Germany) for the Cpdm;Casp11 ${ }^{-1-}$ mice. In the case of the Cpdm;Casp1 $1^{-1-} / 11^{\mathrm{Tg}}$ mice, a KAPA Mouse Genotyping Hot Start Kit (Peqlab, Erlangen, Germany) was used to identify the presence of caspase 11 .

\section{In Vivo Mouse Model of Sepsis}

Mice were injected i.p. with $50 \mathrm{mg} / \mathrm{kg}$ body weight of LPS from Salmonella minnesota (Sigma-Aldrich). LPS was reconstituted in $1 \times$ Dulbecco's phosphate-buffered saline (PBS) buffer (Gibco, Thermo Fisher Scientific, Schwerte, Germany) at 40 $\mu \mathrm{g} / \mu \mathrm{L}$. This solution was used to obtain $50 \mathrm{mg} / \mathrm{kg}$ body weight in $300 \mu \mathrm{L}$ of final volume of $0.9 \% \mathrm{NaCl}$ solution (B. Braun, Melsungen, Germany). At 2 hours after injection, mice were sacrificed by using $4 \mu \mathrm{L} / \mathrm{g}$ body weight of Merial Narcoren $16 \%$ solution (Henry Schein Animal Health, Hallbergmoos, Germany) i.p., to collect the respective samples. Caspase 1 inhibitor II (acetyl-tyrosyl-valyl-alanyl-aspartyl-chloromethylketone; Ac-YVAD-CMK) (ALX-260-028-M005; Enzo Life Sciences, Lörrach, Germany) was injected twice, i.p. at $10 \mathrm{mg} / \mathrm{kg}$ body weight, at 30 minutes before and at the same time with LPS injection. The corresponding dimethyl sulfoxide volume was injected as a control. In the survival experiments, mice were injected i.p. with $50 \mathrm{mg} / \mathrm{kg}$ body weight of LPS and monitored every hour, and the survival time was determined. In this case, the Ac-YVAD-CMK inhibitor was injected 30 minutes before at the same time with LPS injection, and every 2 hours after LPS injection. The corresponding dimethyl sulfoxide volume was injected as a control. Mice were randomly assigned to the control or LPS-injected group. The investigators (M.-V.N., J.Z.-B., H.F., L.T.-H.H., and J.B.) were not blinded to the study groups or analyses.

\section{Cell Culture, Transfection, and in Vitro Caspase 1 Cleavage Assay}

THP-1 cell lines (Sigma-Aldrich) were maintained at $37^{\circ} \mathrm{C}$, in $5 \% \mathrm{CO}_{2}$ in RPMI 1640 (Gibco, Thermo Fisher Scientific) supplemented with $10 \%$ fetal bovine serum (Gibco, Thermo Fisher Scientific), $100 \mathrm{U}$ of penicillin and streptomycin (Gibco, Thermo Fisher Scientific), $2 \mathrm{mmol} / \mathrm{L}$ L-glutamine (Gibco, Thermo Fisher Scientific), and $10 \mathrm{mmol} / \mathrm{L}$ HEPES (SigmaAldrich). Cells tested negative for Mycoplasma contamination. For transfection, $10^{5}$ cells were plated in $1 \mathrm{~mL}$ of RPMI $+10 \%$ fetal bovine serum in a 12-well cell culture plate. A total of 0.5 $\mu \mathrm{g}$ of Strep-SHARPIN-HApcDNA5 plasmid and the empty vector were used in $200 \mu \mathrm{L}$ of OptiMEM (Gibco, Thermo Fisher Scientific). Transfection was performed using Lipofectamine (Life Technologies, Carlsbad, CA). After 18 hours, the medium was changed, and 20 hours after transfection the cells were stimulated with $1 \mu \mathrm{g} / \mathrm{mL}$ Escherichia coli LPS for 16 hours. Serum-free media were changed, and the cells were pulsed with $5 \mathrm{mmol} / \mathrm{L}$ ATP (Sigma-Aldrich) for 1 hour. The supernatant was collected and proteins were precipitated by using trichloroacetic acid. The cells were subjected either to lysis for Western blot analysis or to fluorescence-activated cell sorting analysis after staining with carboxifluorescein-tyrosylvalyl-alanyl-aspartyl-fluoromethylketone (FAM-YVADFMK) (FAM-FLICA Caspase-1 Assay Kit; ImmunoChemistry Technologies, Bloomington, MN). For IL1 $\beta$ measurements in the supernatant, THP- 1 cells were differentiated with $40 \mathrm{ng} / \mathrm{mL}$ phorbol 12-myristate 13-acetate for 18 hours before transfection. For the cleavage assay, ${ }^{26}$ cells were treated overnight with $40 \mathrm{ng} / \mathrm{mL}$ phorbol 12-myristate 13-acetate, fresh media were added, and the cells were differentiated for 3 days. Afterward they were stimulated with $1 \mu \mathrm{g} / \mathrm{mL}$ E. coli LPS for 4 hours. The cells were washed with cold PBS and lysed with $20 \mu \mathrm{L}$ of cleavage buffer (see SDS-PAGE and Western Blot) per $10^{5}$ cells. The lysate was warmed at $30^{\circ} \mathrm{C}$ for 30 minutes. Before warming, the lysate was incubated with $0.5 \mu \mathrm{g}$ of glutathione $S$-transferase (GST)-SHARPIN or GST. After warming, the lysates were subjected to Western blot analysis.

\section{SDS-PAGE and Western Blot}

Lung tissue was lysed in buffer containing $50 \mathrm{mmol} / \mathrm{L}$ Tris- $\mathrm{HCl}$ (pH 8), $150 \mathrm{mmol} / \mathrm{L} \mathrm{NaCl}, 0.02 \% \mathrm{NaN}_{3}, 0.1 \% \mathrm{SDS}, 1 \mu \mathrm{g} / \mathrm{mL}$ aprotinin, $1 \%$ Nonidet P-40, 0.5\% Na-deoxycholate, $100 \mu \mathrm{g} / \mathrm{mL}$ phenyl methyl sulfonyl fluoride, and protease inhibitor mix (10 mmol/L $\varepsilon$-amino-n-caproic acid, 0.5 $\mathrm{mmol} / \mathrm{L}$ benzamidine hydrochloride hydrate, $1 \mathrm{mmol} / \mathrm{L}$ EDTA, $1 \mathrm{mmol} / \mathrm{L}$ N-ethyl maleimide).

THP-1 cell lysates used for the cleavage assay were prepared by using the cleavage buffer HEPES $20 \mathrm{mmol} / \mathrm{L}$ (Tris $\mathrm{pH} 7.5$ ), $10 \mathrm{mmol} / \mathrm{L} \mathrm{KCl}, 1.5 \mathrm{mmol} / \mathrm{L} \mathrm{MgCl}_{2}, 1$ $\mathrm{mmol} / \mathrm{L}$ EDTA, and $1 \mathrm{mmol} / \mathrm{L}$ EGTA, supplemented with $2 \mathrm{mmol} / \mathrm{L}$ dithiothreitol, $2 \mu \mathrm{g} / \mathrm{mL}$ leupeptin, $100 \mu \mathrm{g} / \mathrm{mL}$ phenylmethylsulfonyl fluoride, and $2.5 \mu \mathrm{g} / \mathrm{mL}$ aprotinin.

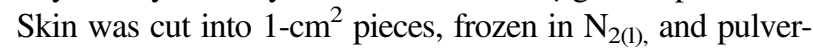
ized using a mortar and pestle. It was then lysed in $1 \mathrm{~mL}$ of lysis buffer containing $10 \mathrm{mmol} / \mathrm{L}$ Tris- $\mathrm{HCl}(\mathrm{pH} 8), 2.5 \mathrm{mmol} / \mathrm{L}$ EDTA, $68.5 \mathrm{mmol} / \mathrm{L} \mathrm{NaCl}, 5 \%$ glycerol (v/v), 0.5\% Triton $\mathrm{X}-100,1 \mathrm{mmol} / \mathrm{L}$ dithiothreitol, $10 \mathrm{mmol} / \mathrm{L} \mathrm{NaF}, 2 \mathrm{mmol} / \mathrm{L}$ $\mathrm{Na}_{3} \mathrm{VO}_{4}, 1 \mathrm{mmol} / \mathrm{L}$ phenyl methyl sulfonyl fluoride, $5 \mu \mathrm{g} / \mathrm{mL}$ aprotinin, $5 \mu \mathrm{g} / \mathrm{mL}$ leupeptin, and $50 \mathrm{nmol} / \mathrm{L}$ okadaic acid.

For SDS-PAGE and Western blot analysis, $100 \mu \mathrm{g}$ (total protein) of sample was mixed with protein loading buffer [250 mmol/L Tris- $\mathrm{HCl}(\mathrm{pH}$ 6.8), 8\% sodium dodecyl sulfate, $40 \%$ glycerol, $8 \% \beta$-mercaptoethanol, and $0.02 \%$ bromophenol blue] and boiled at $95^{\circ} \mathrm{C}$ for 5 minutes.

SDS-PAGE was performed as previously described. ${ }^{27}$ After electrophoresis, the proteins were subjected to transfer to a 
nitrocellulose membrane (Hybond Amersham, GE Healthcare, Freiburg, Germany) at $250 \mathrm{~mA}$ for 40 minutes followed by $350 \mathrm{~mA}$ for 15 minutes. The membrane was blocked in either $5 \%$ milk in Tris-buffered saline with $0.1 \%$ Tween 20 or $1 \times$ Roti-Block (Carl Roth, Karlsruhe, Germany).

Primary antibodies used were mouse monoclonal anti- $\beta$ actin (A5441; Sigma-Aldrich), rat purified anti-caspase 1 (645102; BioLegend, Fell, Germany), caspase 1 p10 antibody (M-20) (sc-514; Santa Cruz Biotechnology, Heidelberg, Germany), caspase 1 p10 antibody (sc-515; Santa Cruz Biotechnology, Hamburg, Germany), caspase 1 p20 antibody (\#2225; Cell Signaling Technology, Leiden, the Netherlands), cleaved caspase 3 (Asp175) (5A1E) rabbit monoclonal antibody (\#9664; Cell Signaling Technology), caspase 11 antibody [17D9] (GTX10454; GeneTex, Irvine, CA), mouse Il1 $\beta / \mathrm{Il} 1 \mathrm{~F} 2$ affinity purified polyclonal antibody (AF-401-NA; R\&D Systems, Wiesbaden, Germany), rabbit anti-RBCK1 (Ras-related nuclearprotein binding protein 2-type and $\mathrm{C}_{3} \mathrm{HC}_{4}$-type zinc finger containing protein ligand-1; HOIL-1L; Ab38540; Abcam, Cambridge, UK), anti-RNF3 (ring finger protein 3)/HOIP antibody (Ab38540; Abcam), and SHARPIN antibody (14626-1AP; Proteintech, Manchester, UK).

Secondary antibodies used were donkey anti-IgG antibody horseradish peroxidase labeled (NA934V; GE Healthcare), polyclonal sheep anti-IgG antibody horseradish peroxidase labeled (NA931V; GE Healthcare), peroxidase-AffiniPure donkey anti-goat IgG (705-035-147; Jackson ImmunoResearch Laboratories), and goat anti-rat IgG (112-005-003; Jackson ImmunoResearch Laboratories). Detection was performed using chemiluminescence with either ECL Plus Western blot analysis detection reagents (GE Healthcare) or SuperSignal West Femto chemiluminescent substrate (Thermo Fisher Scientific).

\section{Enzyme-Linked Immunosorbent Assay}

Tissue samples were treated as described in SDS-PAGE and Western Blot. Blood collected from mice was transferred in heparin (Ratiopharm GmbH, Ulm, Germany) prewashed micro centrifuge tubes, incubated for 15 minutes at room temperature, and centrifuged for 15 minutes at $2000 \times g$.

The following enzyme-linked immunosorbent assay (ELISA) kits were used: mouse Il1//Il-1F2 DuoSet (DY401), mouse TNF- $\alpha$ DuoSet (DY410), mouse CCL2/JE/MCP-1 DuoSet (DY479), human IL18/IL1F4 ELISA (7620), and human IL1 $\beta / I L 1 F 2$ DuoSet (DY201), all from R\&D Systems (Wiesbaden, Germany), and mouse Il18 ELISA kit (7625; MBL International, Woburn, MA).

\section{RNA Isolation, Real-Time Quantitative PCR, and Ethidium Bromide Detection PCR}

Total RNA was isolated using TRI Reagent (Sigma-Aldrich). cDNA was reverse-transcribed using the a High-Capacity
cDNA Reverse Transcription Kit (Applied Biosystems, Darmstadt, Germany).

Real-time quantitative PCR was performed using an AbiPrism 7500 Sequence Detection System (Applied Biosystems).

TaqMan real-time quantitative PCR was performed using TaqMan Fast Universal PCR Master Mix (Applied Biosystems) and the following primers: caspase 1 (Mm00438023_m1), Ccl2 (Mm00441242_m1), Gapdh (4352932E), Il1 $\beta$ (Mm0 0434228_m1), Ill8 (Mm00434225_m1), and Tnf (Mm0 0443260_g1) (Applied Biosystems).

Alternatively, RT ${ }^{2}$ SYBR Green qPCR Master Mix (Qiagen) was used, with the following primers: caspase 11: forward, 5'-GATGCCAAAAAGAAACACAGC- $3^{\prime}$, and reverse, $5^{\prime}$-CTCCATTTCCAGATTAGCTTCACC-3'; Gapdh: forward, 5'-CATGGCCTTCCGTGTTCCTA- $3^{\prime}$ and reverse, 5'-CCTGCTTCACCACCTTCTTGAT- $3^{\prime}$.

Caspase 1 cDNA was also amplified using a HotStarTaq Master Mix Kit (Qiagen) and visualized with ethidium bromide after agarose gel electrophoresis. The following primers were used: caspase 1 : forward, 5'-GATTCTAAAGGAGGACATCC-3' and reverse, 5'-GTAAATGAACTGGA-3'; Gapdh: forward, $5^{\prime}$-CATCTTCCAGGAGCGAGACC-3' and reverse, $5^{\prime}$-CTGTGGTCATGAGCCCTTCC-3' .

\section{GST Protein Purification}

GST fusion proteins of human SHARPIN and mutant variant SHARPIN $\Delta \mathrm{C}$ (1-232) containing only the first 232 $\mathrm{N}$-terminal amino acid residues of SHARPIN were purified essentially as previously described. ${ }^{15}$ In brief, transformed E. coli BL21(DE3) cells were grown in Luria-Bertani medium until $\mathrm{OD}_{600} 0.7$ to 0.8 and induced with $0.5 \mathrm{mmol} / \mathrm{L}$ isopropyl- $\beta$-D-thiogalactoside. After 3 hours, bacteria were harvested and lysed by sonication in cold $0.01 \%$ Triton $\mathrm{X}-100$ in PBS containing protease inhibitors. The lysate was incubated on glutathione sepharose beads for 3 hours and afterward washed successively with cold PBS. The beads immobilized with the GST fusion proteins were further used for GST pull-down assays.

\section{GST Pull-Down Assays}

Purified recombinant human active caspase 1 (Enzo Life Sciences, Lausen, Switzerland) was incubated with GST proteins conjugated to glutathione sepharose beads at $4{ }^{\circ} \mathrm{C}$ for 1 hour. After washing four to five times with PBS containing $300 \mathrm{mmol} / \mathrm{L} \mathrm{NaCl}$, the beads were lysed in protein loading buffer and analyzed via SDS-PAGE and Western blot.

\section{Competition Experiment}

Five micrograms of anti-cleaved caspase 1 p20 antibody (sc22163; Santa Cruz Biotechnology, Heidelberg, Germany) was immobilized on beads (Pierce Co-Immunoprecipitation Kit; Thermo Fisher Scientific). A total of $0.75 \mu \mathrm{g}(100 \mathrm{nmol} / \mathrm{L})$ 
of recombinant active caspase 1 consisting of p20/p10 dimers (approximately $30 \mathrm{kDa}$ ) were retained on the p20 antibodybased columns. Purified SHARPIN $\Delta C$ (1-232) (approximately $23 \mathrm{kDa}$ ) was added onto the active caspase 1-based columns at different concentrations $(0.1,0.5$, and $1 \mu \mathrm{mol} / \mathrm{L})$. After washing, the samples were eluted and subjected to Western blot analysis.

\section{Histologic Analysis}

Tissue samples were fixed and embedded in paraffin. For analysis, $4-\mu \mathrm{m}$-thick slides were treated in xylol for paraffin removal, then rehydrated using successive treatment with $100 \%, 95 \%, 70 \%$, and $50 \%$ ethanol solution and $\mathrm{H}_{2} \mathrm{O}$ for 3 minutes each.

For periodic acid-Schiff staining, slides were incubated for 5 minutes with $0.8 \%$ periodic acid to achieve the oxidation reaction. Afterward the slides were rinsed with distilled water three times and incubated for 15 minutes with Schiff reagent (Carl Roth) at room temperature. The slides were washed with tap water two times for $5 \mathrm{mi}$ nutes. Counterstaining was performed by using Mayer's Hematoxylin Solution (Sigma-Aldrich, Munich, Germany). After the final washing step with tap water, the slides were covered with glycerol/gelatin (Sigma-Aldrich, Munich, Germany).

\section{Confocal Microscopy}

THP-1 cells $\left(1 \times 10^{4}\right)$ were grown on $0.2 \%$ gelatin-coated eight-chamber slides (Nunc; Thermo Fisher Scientific). After LPS + ATP treatment, cells were washed with PBS and fixed for 30 minutes in $4 \%$ paraformaldehyde at $4{ }^{\circ} \mathrm{C}$. After permeabilization with $0.1 \%$ Triton X-100 for $30 \mathrm{sec}$ onds and blocking in PBS, 5\% bovine serum albumin, cells were incubated overnight with the goat anti-cleaved caspase 1 p20 (sc22163; Santa Cruz Biotechnology, Heidelberg, Germany) or rabbit anti-SHARPIN antibody (14626-1-AP; Proteintech), washed in PBS, and then incubated with donkey anti-goat IgG Alexa Fluor 488 or donkey anti-rabbit IgG Alexa Fluor 594, for 1 hour. Nuclei were visualized with DAPI (Vector Laboratories, Burlingame, CA). A Zeiss LSM-510 confocal laser-scanning microscope (Carl Zeiss, Oberkochen, Germany) was utilized for the acquisition of confocal images with a $\times 63,1.3$ oil-immersion objective. Merged images represent single optical sections $(<0.8 \mu \mathrm{m})$, collected with the pinhole set to 1 airy unit for the red channel, and adjusted to give the same optical slice thickness in the green and blue channels. Images were acquired in single confocal planes to determine colocalization using Zeiss LSM-510 software version 5.0.0.267 (Carl Zeiss), with filters set at $488 / 594 \mathrm{~nm}$ for dual-channel imaging. All images were analyzed using ImageJ software version 1.4.3.67 (NIH, Bethesda, MD; http://imagej.nih.gov/ij) and Adobe Photoshop CS6 (Adobe Systems, San Jose, CA). Line scanning was utilized to further quantify colocalization of SHARPIN and caspase 1. This technique gives measurements of the pixels along a single defined axis along the specimen to define localization of two differentially labeled fluorophores. A qualitative assessment of a proximitydependent localization between the two potentially interacting molecules is obtained from measuring the extent of overlap, defined as two different fluorescent labels displaying independent emission wavelengths that occupy the same pixel.

Colocalization analysis was performed using the ImageJ colocalization color map plugin. ${ }^{28}$ Colocalization was performed on single, segmented cells. The index of colocalization is represented on the $y$ axis.

\section{Co-Immunoprecipitation}

Co-immunoprecipitation was performed by using a Pierce Co-Immunoprecipitation Kit (Thermo Fisher Scientific). Five micrograms of antibody recognizing the bait protein were immobilized. A total of $6.5 \mathrm{mg}$ of lysate was incubated with the antibody resin overnight at $4^{\circ} \mathrm{C}$. After washing, the complex bait-prey proteins were eluted by using $50 \mu \mathrm{L}$ of elution buffer containing primary amines ( $\mathrm{pH} 2.8$ ). The following antibodies against bait proteins were used: rat purified anti-caspase 1 (645102; Biolegend), caspase 11 antibody [17D9] (GTX10454; GeneTex, Herford, Germany), cleaved caspase 1 p20 antibody (sc22163; Santa Cruz Biotechnology, Heidelberg, Germany).

\section{Microscale Thermophoresis}

To study the binding between SHARPIN and caspase 1, purified human GST-SHARPIN was labeled with the red fluorescent dye NT-647 by using a Monolith Protein Labeling Kit Red (NanoTemper Technologies, Munich, Germany). As a control, GST protein was labeled in the same manner. Human caspase 1 protein (Enzo Life Sciences, Lausen, Switzerland) was titrated in concentrations in the range of 0.488 to $1000 \mathrm{nmol} / \mathrm{L}$. Before loading onto the capillaries, the tubes were centrifuged for 5 minutes at maximum speed. For measurements the Monolith NT.115 device (NanoTemper Technologies) was used, and for data analysis the NT Analysis software version 1.427 (NanoTemper Technologies) was used. Parameters used were: laser power, 100\%; LED, 80; laser on-time, 30 seconds; laser off-time, 5 seconds; and temperature, $25^{\circ} \mathrm{C}$.

The normalized fluorescence,

$$
F_{\text {norm }}=F_{\text {hot }} / F_{\text {cold }}
$$

is correlated to the fraction of molecules existing in the bound and unbound forms by ${ }^{29}$ :

$$
\mathrm{F}_{\text {norm }}=(1-\mathrm{x}) \mathrm{F}_{\text {norm }}(\text { unbound })+\mathrm{xF}_{\text {norm }}(\text { bound }),
$$

where $x$ is the fraction of molecules bound to their targets, $F_{\text {norm }}$ (unbound) is the normalized fluorescence of unbound labeled molecules, and $F_{\text {norm}}$ (bound) is the 
A

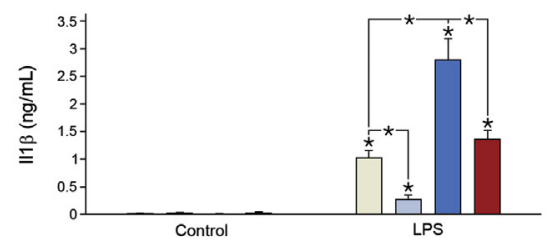

C

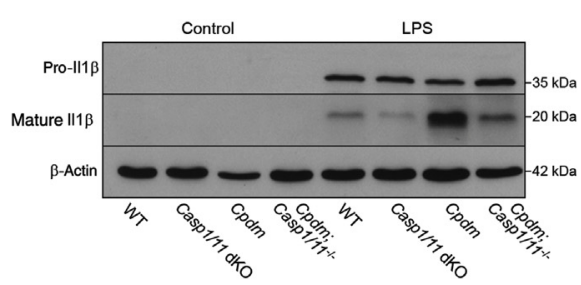

E

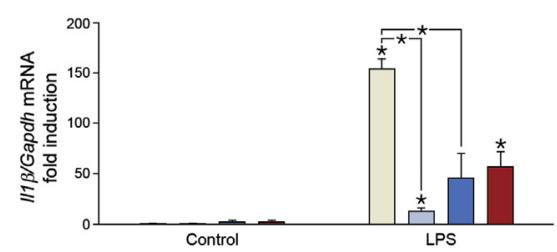

G

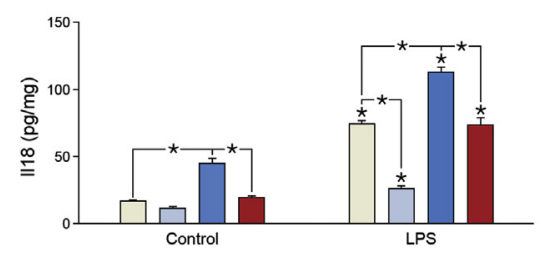

I

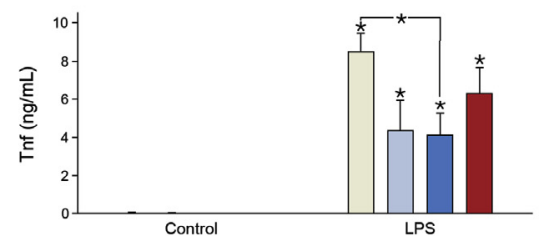

B

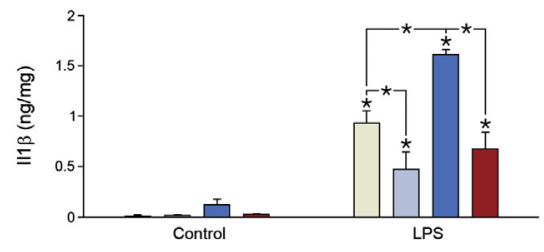

D

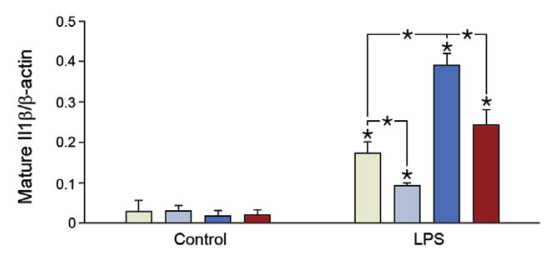

$F$

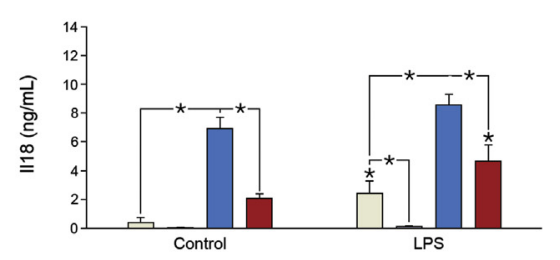

H

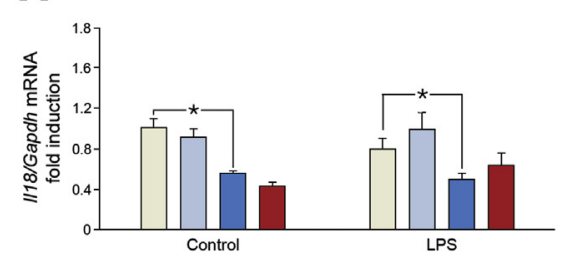

J

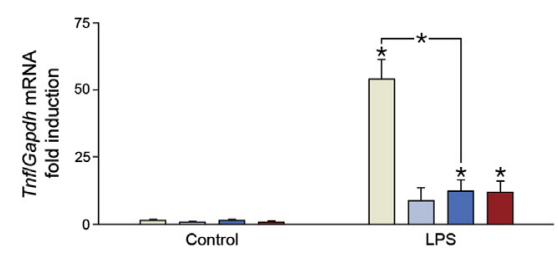

Figure 1 Caspase 1 deficiency rescues overproduction of Il1 $\beta /$ Il18 in plasma and lungs of endotoxemic Cpdm mice. WT, white bars; Casp1/11 $\mathrm{dKO}$, light blue bars; Cpdm, dark blue bars; Cpdm;Casp1 $111^{-/-}$, red bars. A and B: ELISA for Il1 $\beta$ in plasma (A) and lung (B) whole cell lysates derived from mice with the indicated genotypes. C and D: Representative immunoblot of Il1 $\beta$ in lungs from mice with the indicated genotypes (C) and densitometric quantification of the band representing mature Il $1 \beta$ normalized to $\beta$-actin (D). E: Real-time quantitative PCR (qPCR) of Il1 $\beta$ normalized to glyceraldehyde-3-phosphate dehydrogenase (Gapdh) in murine lungs. $\mathbf{F}$ and G: ELISA for Il18 in plasma (F) and lungs (G) from the indicated genotypes. H: qPCR of Il18 normalized to Gapdh in murine lungs. I: ELISA for tumor necrosis factor (Tnf) in plasma from mice with the indicated genotypes. J: qPCR of Tnf normalized to Gapdh in lungs from mice with the indicated genotypes. Sepsis was induced with lipopolysaccharide (LPS) $50 \mathrm{mg} / \mathrm{kg}$ for 2 hours. Data are expressed as means \pm SEM. $n=3$ mice per group (D and $\mathbf{G}) ; n=3$ to 4 mice per group $(\mathbf{H}) ; n=6$ mice per group $(\mathbf{A}, \mathbf{E}, \mathbf{F}, \mathbf{I}$, and $\mathbf{J}) .{ }^{*} P<0.05$ versus wild type (WT) or controls (unpaired two-tailed $t$-test). normalized fluorescence of labeled molecules bound to their unlabeled targets. $F_{\text {norm }}[\%$ oo was plotted against the concentration of the unlabeled molecule, resulting in a sigmoidal dependence if the unlabeled and labeled molecules interact; from this graph the dissociation constant was directly obtained. 29

\section{Statistical Analysis}

Data are presented as means \pm SEM. Results are representative of three or more individual experiments. For comparison of two groups, an unpaired two-tailed $t$-test was used, and results were considered significant at $P<0.05$.

\section{Results}

SHARPIN Deficiency Results in Enhancement of Mature Il1 $\beta /$ Il18 and Active Caspase 1 in the Lung and Plasma of Endotoxemic Cpdm Mice

We investigated the role of Sharpin in the regulation of the caspase $1 / \mathrm{Il1}$ pathway in $\mathrm{Cpdm}$ mice. ${ }^{20}$ We analyzed maturation of Il1 $\beta$ and Il18 as well as activation of caspases 1 and 11 in plasma and lungs of nontreated and LPS-treated mice. LPS is an in vivo trigger of both Il1 $\beta$ transcription through $\mathrm{NF}-\kappa \mathrm{B}$ as well as caspase 1 activation. We found higher levels of mature Il1 $\beta / 18$ in the plasma (Figure 1, A and F) and lung (Figure 1, B-D and G) of LPS-treated Cpdm mice 
A

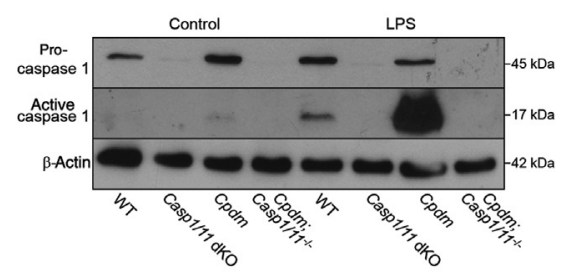

C

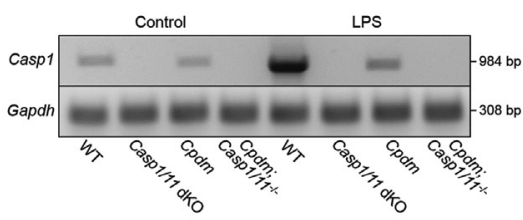

$\mathbf{E}$

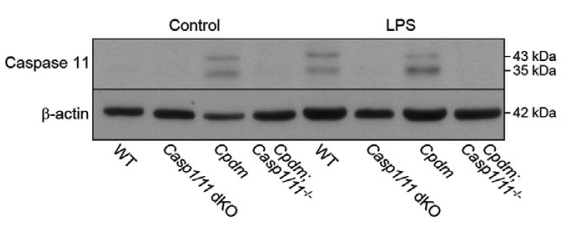

B

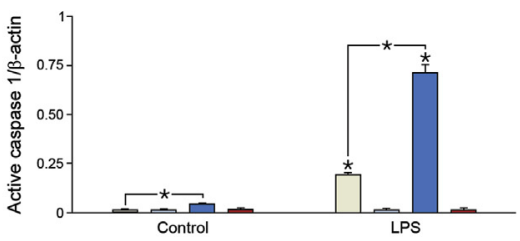

D

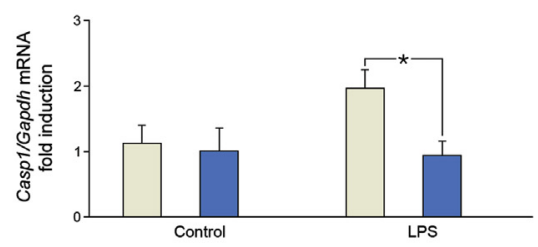

$\mathbf{F}$

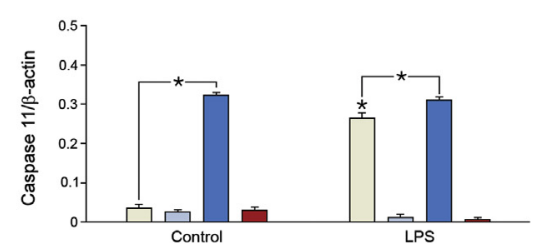

Figure 2 Increased levels of active caspase (Casp) 1 and 11 in lungs from Cpdm mice. WT, white bars; Casp1/11 dK0, light blue bars; C $p d m$, dark blue bars; Cpdm;Casp1/11 ${ }^{-/-}$, red bars. A and B: Representative immunoblot of pro- and active Casp1 in lungs from mice with the indicated genotypes (A) and densitometric quantification of the bands representing active Casp1 normalized to $\beta$-actin (B). C and D: Casp1 and Gapdh gene expression in lungs derived from mice with the indicated genotypes, as visualized by agarose gel electrophoresis of amplified Casp1 or Gapdh cDNA after reverse transcription and PCR (C) and realtime quantitative PCR (qPCR) of Casp1 normalized to Gapdh in lungs from wild-type (WT) and Cpdm mice (D). E and F: Representative immunoblot of the two Casp11 isoforms (43 and $35 \mathrm{kDa}$, respectively) from mice with the indicated genotypes (E), and densitometric quantification of these two Casp11 isoforms normalized to $\beta$ actin (F). Sepsis was induced with lipopolysaccharide (LPS) $50 \mathrm{mg} / \mathrm{kg}$ for 2 hours. Data are expressed as means \pm SEM. $n=3$ (B and $\mathbf{F})$; $n=4$ mice per group (D). ${ }^{*} P<0.05$ versus WT or controls (unpaired two-tailed $t$-test). dKO, double knockout. compared to WT. The lung was chosen as a target organ as it is one of the most affected in endotoxic shock. Il18 (Figure 1, F and $G$ ) was markedly enhanced in plasma (Figure $1 F$ ) and lungs (Figure $1 \mathrm{G}$ ) of nontreated Cpdm mice. However, pulmonary Il1 $\beta$ (Figure 1E) and Il18 (Figure 1H) mRNA levels were reduced in $C p d m$ mice. The discrepancy between protein and mRNA levels was specific for Il1 $\beta / 18$, whereas the NF$\kappa \mathrm{B}$-induced cytokine, Tnf was down-regulated in plasma (Figure 1I) and lungs (Figure 1J) of Cpdm mice.

Thus, we investigated whether enhancement of active caspase 1 and its potential upstream activator, caspase $11,^{30-32}$ could be linked to the elevation of mature Il $\beta / 18$ in $C p d m$ mice under LPS-induced endotoxemia in lung. We found a substantial increase in the pulmonary active caspase 1 in LPS-treated $C p d m$ mice and a slight elevation in untreated Cpdm (Figure 2, A and B), even though Caspl mRNA was decreased (Figure 2, C and D) compared to WT. This finding was associated with enhanced pulmonary caspase 11 (Figure 2, E and F) in Cpdm mice, in nontreated and LPS-treated mice. Thus, Sharpin deficiency results in an increment of active caspase 1 and mature Il1 $\beta / 18$, which is pronounced in endotoxic shock.

\section{Caspase 1 Is the Main Inducer of Il1 $\beta /$ Il18 in Endotoxemic Sharpin-Deficient Mice}

To provide genetic proof of the role of caspase 1 in the generation of mature Il1 $\beta / 18$ in $C p d m$ mice and to define the role for caspase 11 in this process, we crossed Cpdm mice with mice deficient in caspase $1\left(\right.$ Casp $\left.^{-/-} / 11^{\mathrm{Tg}}\right)$, caspase 11 (Casp11 $1^{-/-}$), or both enzymes (Casp1/11 double knockout). We investigated caspase 1 -dependent enhancement of mature Il1 $\beta / 18$ during LPS-induced endotoxemia. Under these conditions, Cpdm;Casp $1 / 11^{-/-}$mice exhibited significantly lower levels of circulating (Figure 1A) and pulmonary (Figure 1, B-D) Il1 $\beta$ as compared to those in Cpdm mice. Plasma Il1 $\beta$ levels of Cpdm;Casp $1 / 11^{-1-}$ mice were comparable to those of $C p d m ; C a s p 1^{-/-} / 11^{\text {Tg }}$ mice (Figure $3 \mathrm{~A}$ ). Cpdm;Casp $11^{-/-}$mice also displayed reduced plasma Il1 $\beta$ levels, but these did not reach statistical significance (Figure 3A). Similar variations in Il1 $\beta$ levels were also observed among septic control mice (WT, Casp $11^{-1-}$, Casp $^{-/-} / 11^{\mathrm{Tg}}$ and Casp1/11 double knockout) without a Cpdm background (Figure 3A). Consequently, we confirmed that caspase 1 is the main contributor of Il1 $\beta$ maturation in $C p d m$ mice during endotoxemia. In comparison, lack of caspase 11 in $C p d m$ mice decreased Il1 $\beta$ plasma levels insignificantly compared to the ablation of only caspase 1 (Cpdm;Casp1 ${ }^{-1-} / 11^{\mathrm{Tg}}$ mice) or both caspases 1 and 11 (Cpdm;Casp1/11 $1^{-/-}$). However, it is notable that absence of both caspases 1 and 11 did not reduce completely the Il1 $\beta$ levels in Cpdm mice. This finding might be explained by the existence of other enzymes that were shown to be involved directly in the maturation of Il1 $\beta$ cytokine ${ }^{33}$ (eg, metalloproteinases $^{34}$ or granzyme A). ${ }^{35}$

Under nonstimulated and LPS-treated conditions, plasma (Figure 1F) and pulmonary (Figure 1G) levels of Il18 in Cpdm mice were significantly reduced when both caspases 1 and 11 were absent. Il18 plasma levels 

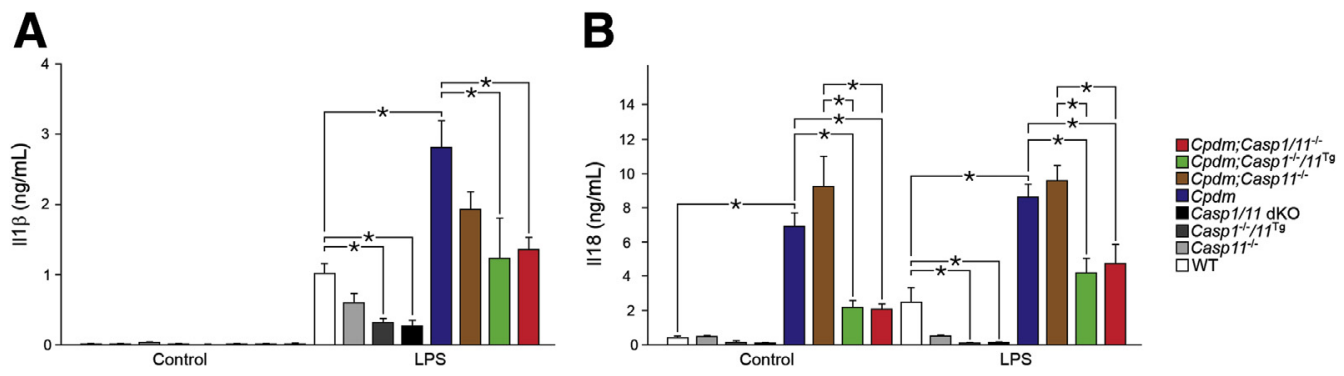

Figure 3 Levels of Il1 $\beta / \mathrm{Il} 18$ in plasma from all investigated mouse strains under normal and endotoxemic conditions. A and B: Enzyme-linked immunosorbent assay for Il1 $\beta$ (A) and Il18 (B) in mouse plasma. Sepsis was induced with lipopolysaccharide (LPS) $50 \mathrm{mg} / \mathrm{kg}$ for 2 hours. Data are expressed as means \pm SEM. $n=4$ to 6 mice per group $(\mathbf{A}) ; n=5$ or 6 mice per group (B). ${ }^{*} P<0.05$ versus WT or controls (unpaired two-tailed $t$-test). dK0, double knockout.

in LPS-treated and -nontreated Cpdm;Casp $1 / 11^{-1-}$ mice

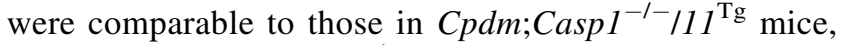
whereas $C p d m ; C_{\text {Casp } 11^{-1-}}$ mice did not show any rescue in Il18 levels as compared to $C p d m$ mice (Figure 3B). Thus, as opposed to caspase 11, caspase 1 is the main inducer of II18 in both control and endotoxemic Cpdm mice. However, as the levels of $\mathrm{Il18}$ were not completely reduced, we presume that other enzymes shown previously to process Il18 are involved in Il18 maturation in Cpdm mice (eg, granzyme $\mathrm{G}$, elastase). ${ }^{36}$

\section{Caspase 1 Deficiency but not Caspase 11 Prevents Inflammation in Cpdm Mice}

Having obtained mutant mice with deficiencies in the Sharpin gene and caspase 1/11 genes, we tested the effects of Casp1/11 double deficiency on multiorgan abnormalities in $C p d m$ mice. ${ }^{20,37-39}$ Ablation of caspase 1, either autonomously or in combination with caspase 11 in Sharpin-deficient mice, allowed the mice to reach sexual maturity and to breed. It rescued the macroscopic skin lesions (Supplemental Figure S1A) and normalized their lifespan (Supplemental Figure S1B). Lifespan monitoring had to be interrupted in Cpdm and Cpdm;Casp11 ${ }^{-1-}$ mice at 23 weeks due to severe skin lesions (Supplemental Figure S1B). Additionally, reduction in body weight (Supplemental Figure S1C) and splenomegaly in $C p d m$ versus WT mice (Supplemental Figure S1D) were significantly rescued only in $C p d m ; C a s p 1 / 11^{-1-}$ but not in Cpdm;Casp1 ${ }^{-1-} / 11^{\mathrm{Tg}}$ and Cpdm;Casp $11^{-1-}$ mice.

Furthermore, the deficit in IgG (Supplemental Figure S1E) and surplus of IgM (Supplemental Figure S1F) in $C p d m$ mice $^{38}$ were restored to normal by either caspase 1 or both caspases 1 and 11 deficiency for $\mathrm{IgG}$ and by double ablation for IgM. In contrast to caspase 11 loss, which did not affect the hepatitis in $C p d m$ mice, caspase 1 loss rescued the hepatic phenotype (Supplemental Figure S1G).

\section{Caspase 1 but not Caspase 11 Ablation Rescues the Skin Phenotype in $\mathrm{C} p d m$ Mice}

Cpdm skin showed immune cell infiltrates in the dermis with para- and hyperkeratosis in the epidermis (Supplemental
Figure S2A), as previously reported. ${ }^{20}$ Lack of both caspases 1 and 11 reduced both the dermal infiltrates and the epidermal thickness (Supplemental Figure S2A). Unlike caspase 11, the absence of caspase 1 alone rescued the inflammatory skin phenotype in $C p d m$ mice (Supplemental Figure S2A). ELISA showed high levels of Il1 $\beta$ (Supplemental Figure S2B) and Il18 (Supplemental Figure S2C) in the skin of Cpdm mice; these levels were significantly attenuated by loss of both caspases 1 and 11 , or caspase 1 or 11 individually (Supplemental Figure S2, B and C). In Cpdm mice, depletion of caspase 11 alone led to a decrease in Il1 $\beta / 18$ (Supplemental Figure S2, B and C). However, this effect was significantly smaller than the reductions observed in $C p d m ; \operatorname{Caspl}^{-1-} / 11^{\mathrm{Tg}}$ and Cpdm;Casp $1 / 11^{-1-}$ mice.

\section{Secondary Lymphoid Organ Development Is Not Rescued by Caspase 1 Knockout}

Not all immunologic defects in Sharpin-deficient mice are rescued by caspase 1 loss. The abnormal splenic architecture in $C p d m$ mice $^{22,38}$ was not affected by ablation of caspase 1 and/or caspase 11 (Supplemental Figure S3A). Peyer's patches were absent in $C p d m$ mice $^{40}$ and did not recover after loss of caspase 1 and/or caspase 11 (Supplemental Figure S3B).

\section{Pharmacologic Inhibition of Caspase 1 Prolongs Survival and Reduces Splenic Apoptosis in Sharpin- Deficient Endotoxemic Mice}

Next, we determined whether caspase 1 inhibition could improve the poor survival in endotoxemic $C p d m$ mice. ${ }^{41}$ To this end, we treated LPS-injected $C p d m$ mice with $10 \mathrm{mg} / \mathrm{kg}$ of Ac-YVAD-CMK caspase 1 inhibitor on a 2-hourly basis. Ac-YVAD-CMK is an irreversible inhibitor of caspase 1 used previously in several reports to reduce the LPS lethality in vivo in WT animals. ${ }^{42,43}$ We analyzed the survival rate (Figure 4A), splenic apoptosis (Figure 4B), and Il1 $\beta$ plasma levels (Figure 4C) to see whether the inhibition of caspase 1 might improve the outcome of endotoxic shock in $\mathrm{Cpdm}$ mice in a fashion similar to genetic ablation (Figure 4, A-C). After LPS 
A

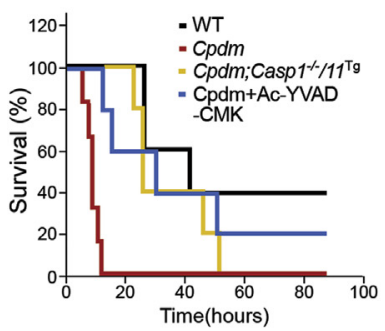

D

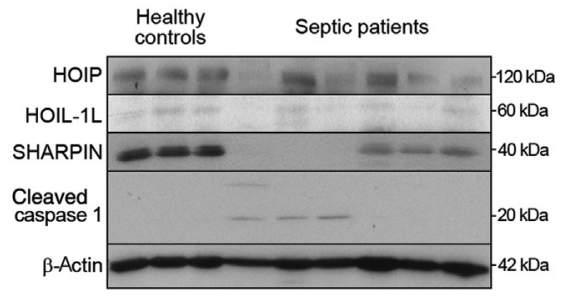

H

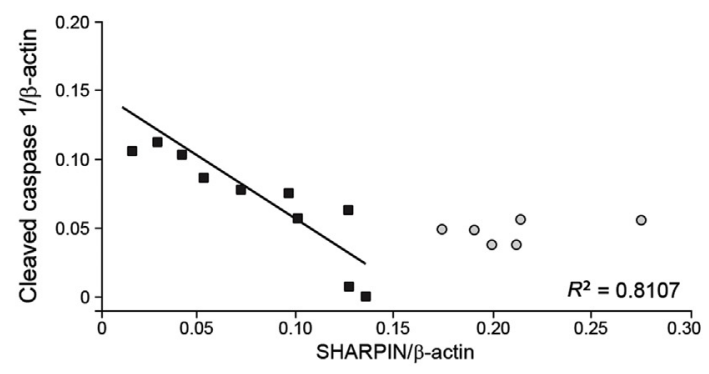

J

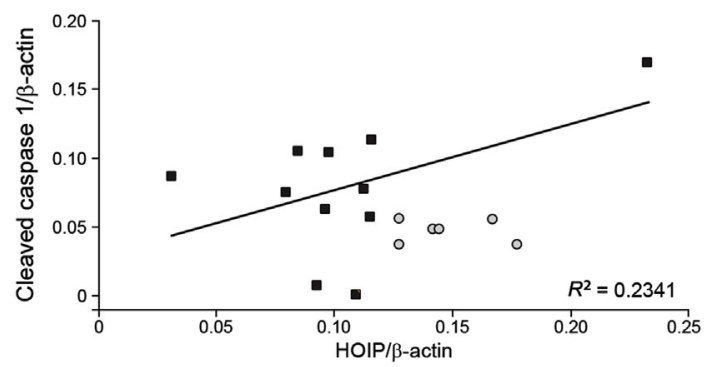

B

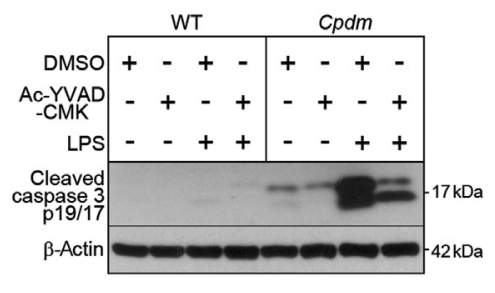

E

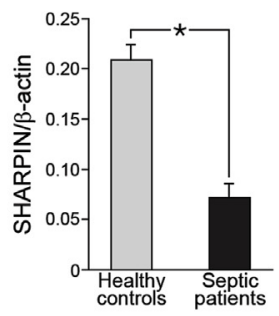

C

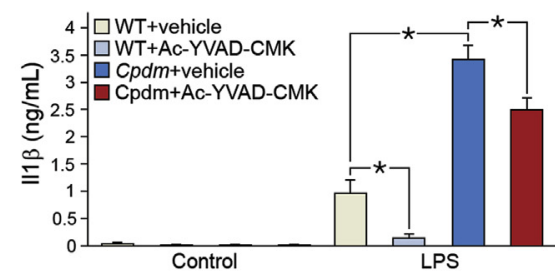

F
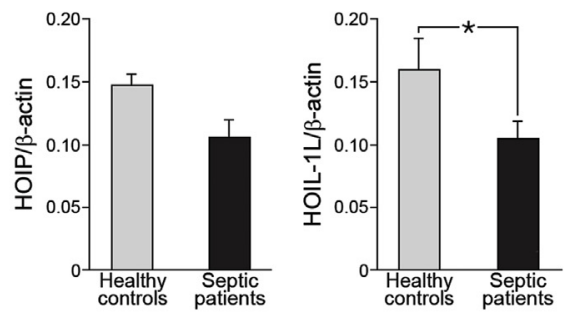

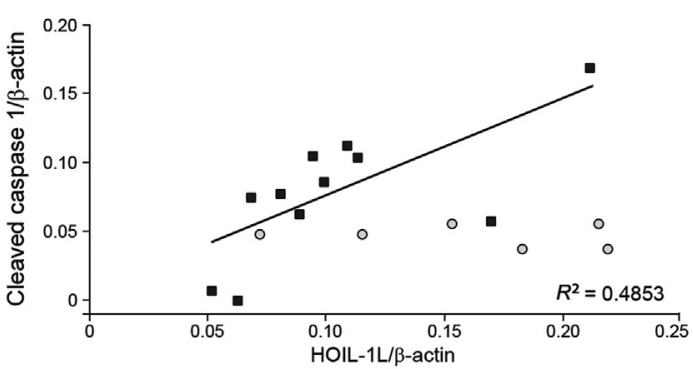

K

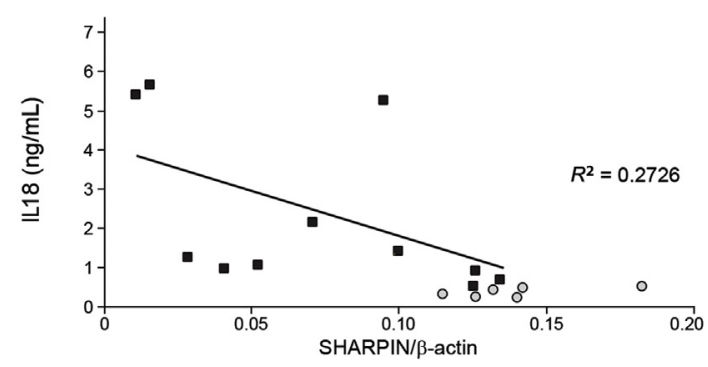

Figure 4 Pharmacologic inhibition of caspase 1 in Cpdm endotoxemic mice and correlation of SHARPIN and active caspase 1 levels in peripheral blood mononuclear cells (PBMCs) from septic patients. A: Survival of the wild-type (WT), Cpdm, Cpdm + caspase 1 inhibitor (Ac-YVAD-CMK), and Cpdm;Casp1 ${ }^{-/-} / 11^{\top 9}$ mice after a lethal dose $(50 \mathrm{mg} / \mathrm{kg}$ ) of lipopolysaccharide (LPS). B: Representative immunoblot of active caspase 3 in spleens from WT and Cpdm mice after inhibition with Ac-YVAD-CMK under control and endotoxemic (2 hours) conditions. C: Plasma levels of Il1 $\beta$ after inhibition with Ac-YVAD-CMK in endotoxemic WT and Cpdm mice as determined by enzyme-linked immunosorbent assay. D-K: Analysis of PBMC lysates from healthy control subjects (open circles) and septic patients (closed squares). Lysates were probed by Western blots (D), followed by densitometric analysis of the resulting bands normalized to $\beta$-actin (E-G). Levels of SHARPIN (E), HOIP (F), and HOIL-1L (G) in septic patients vis-à-vis healthy controls. Levels of cleaved caspase 1 in septic patients were plotted against levels of SHARPIN (H), HOIP (I), and HOIL-1L (J). Plasma levels of Il18 were plotted against levels of SHARPIN (K). Data are expressed as means \pm SEM. $n=3$ mice per group (B); $n=4$ or 5 (C); $n=6$ (D-K, healthy subjects); $n=11$ (D-K, septic patients). ${ }^{*} P<0.05$ (unpaired two-tailed $t$-test). DMSO, dimethyl sulfoxide.

injection, the Cpdm mice survived for a much shorter time period than WT mice did. Notably, caspase 1 inhibition prolonged survival in Sharpin-deficient endotoxemic mice to an extent comparable to the genetic loss of caspase 1
(Figure 4A). Moreover, caspase 1 inhibition blocked splenic apoptosis in Sharpin-deficient controls and endotoxemic mice, as detected by a reduction in cleaved caspase 3 (Figure 4B). 


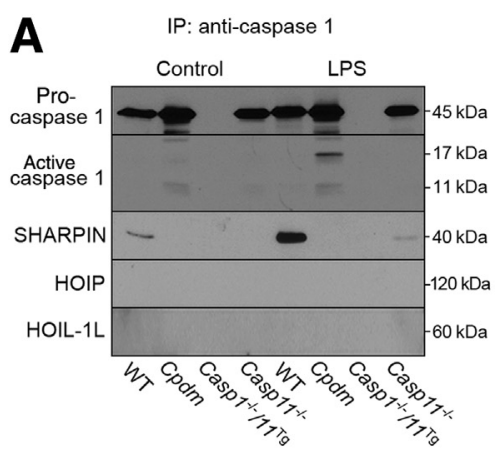

D
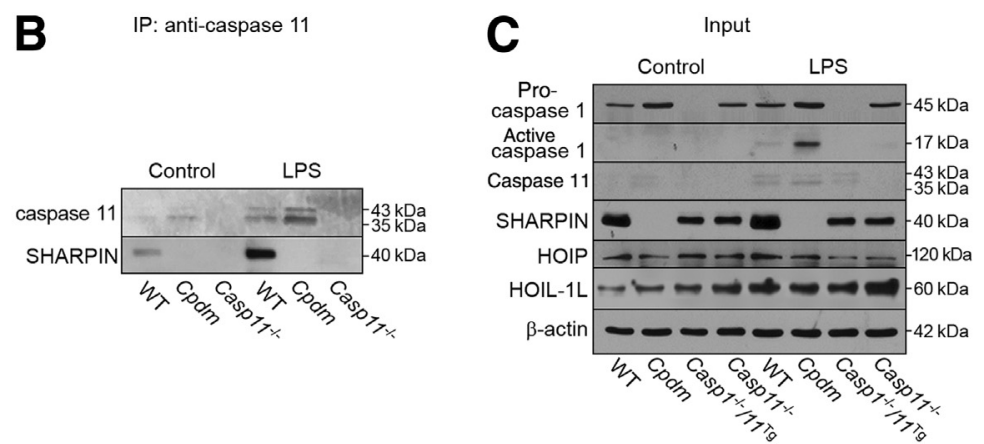

$\mathbf{E}$
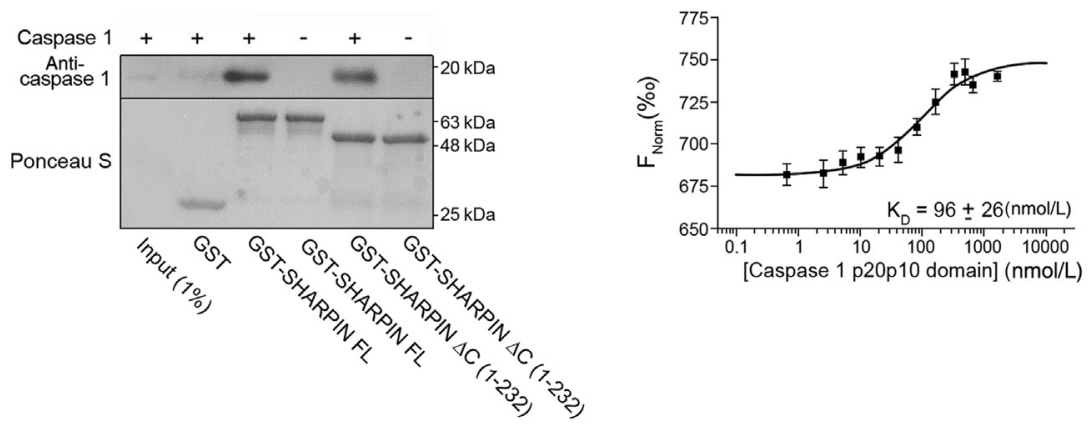

Figure 5 SHARPIN binding to caspase 1. A and B: Co-immunoprecipitation (IP) with anti-caspase 1 (A) and anti-caspase 11 (B) antibodies in lung lysates from control and endotoxemic mice with the indicated genotypes. C: Western blot of lung lysates used for the co-IP. D: Pull-down using glutathione S-transferase (GST)tagged full-length SHARPIN and SHARPIN $\Delta C(1-232)$ and recombinant active caspase 1 . Western blot shows caspase 1 p20 in direct interaction with both full-length SHARPIN and SHARPIN $\triangle C$ (1-232). Ponceau S shows input of GST fusion proteins. E: GST-SHARPIN binding to caspase 1 assayed by microscale thermophoresis. Data are expressed as means \pm SEM. $n=3$. FL, full-length; $\mathrm{F}_{\text {Norm, }}$ normalized fluorescence; HOIL-1L, heme-oxidized iron regulatory protein 2 ligase-1; HOIP, HOIL$1 \mathrm{~L}$-interacting protein; $\mathrm{K}_{\mathrm{D}}$, dissociation constant; LPS, lipopolysaccharide; WT, wild type.

\section{Levels of SHARPIN in Peripheral Blood Mononuclear Cells from Septic Patients Negatively Correlate with the Levels of Active Caspase 1}

To provide a link between the studies using mutant mice and human inflammatory conditions, we studied in septic patients a possible correlation between the expression levels of SHARPIN in peripheral blood mononuclear cells (PBMCs) and levels of active caspase 1 and whether this effect is specific for SHARPIN only or also for the LUBAC components HOIL-1 and HOIP. Accordingly, we evaluated by Western blot the expression of SHARPIN, HOIL-1L, HOIP, and active caspase 1 in PBMCs isolated from late-stage septic patients, whose clinical characteristics are listed in Supplemental Table S1. First, we observed that the levels of all three LUBAC components, SHARPIN (Figure 4, D and E), HOIP (Figure 4, D and F), and HOIL-1L (Figure 4, D and G), varied among the septic patients. Of these, levels of SHARPIN and HOIL-1L were significantly down-regulated vis-à-vis healthy volunteers, whereas levels of HOIP, while slightly lower in septic patients, did not reach statistical significance. Only SHARPIN levels negatively correlated with active caspase 1 levels in PBMC lysates $\left(R^{2}=\right.$ 0.8107) (Figure $4 \mathrm{H}$ ). In contrast, active caspase 1 levels weakly and positively correlated with HOIP (Figure 4I) and positively correlated with HOIL-1L (Figure 4J). These findings might support the potential role of SHARPIN as a negative regulator of inflammation through caspase 1 . The different correlation pattern observed for active caspase 1/HOIL-1L confirms rather its role described previously as an activator of the inflammasome/caspase 1 pathway. ${ }^{44}$ We also analyzed levels of SHARPIN expression in PBMC lysates with serum levels of mature IL18 (Figure $4 \mathrm{~K}$ ) and found a negative correlation, but with a much lower correlation factor $\left(R^{2}=0.2726\right)$ (Figure $4 \mathrm{~K}$ ) than with levels of active caspase 1 in PBMCs. It is notable that although secreted IL18 was found to be abundant in the serum of septic patients compared to healthy volunteers, the levels of IL $1 \beta$ were very low, close to the lower limit of detection (data not shown). These independent and unbiased observations in humans corroborate the conclusions drawn from our murine studies regarding the role of SHARPIN as a negative regulator of caspase 1 activation. However, the same is valid for neither HOIL-1L nor HOIP, which positively correlate with caspase 1 activation.

\section{SHARPIN Binds to Caspase 1 in Vivo in Lungs}

Given the role of SHARPIN deficiency in modulating caspase 1 activation in the mutant $C p d m$ mice, we tested the physical interaction between SHARPIN and caspase 1/11 using co-immunoprecipitation of lung extracts. We found SHARPIN protein in complex with caspase 1 (Figure 5A) 
A

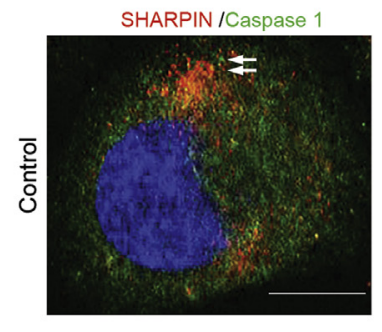

SHARPIN /Caspase 1

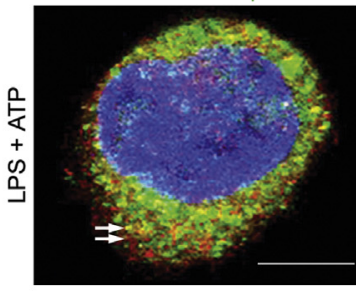

B
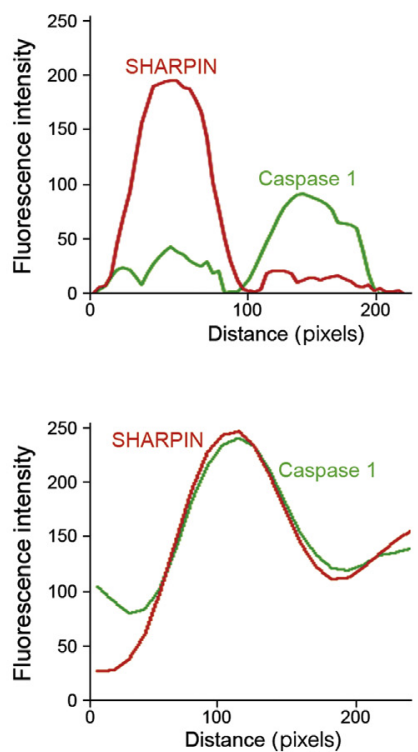

C

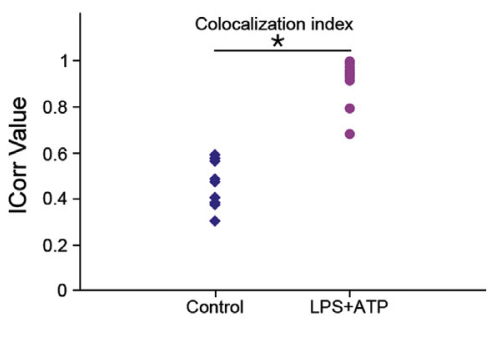

D

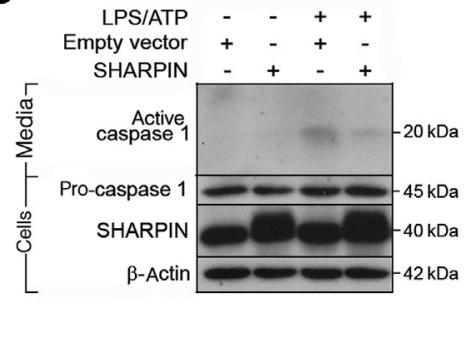

E

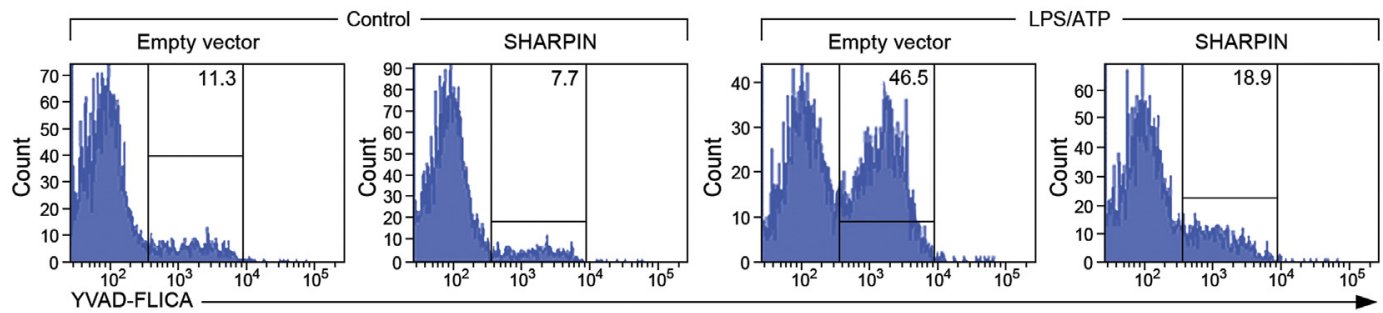

F

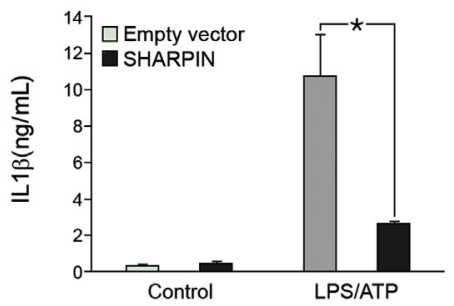

I

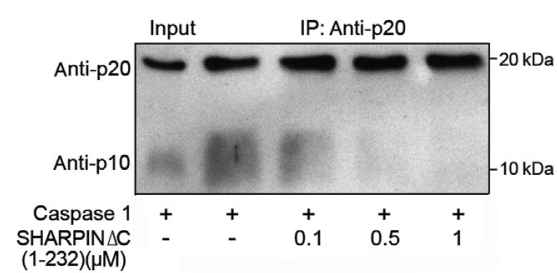

G

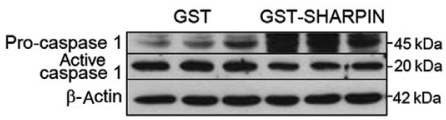

J
H
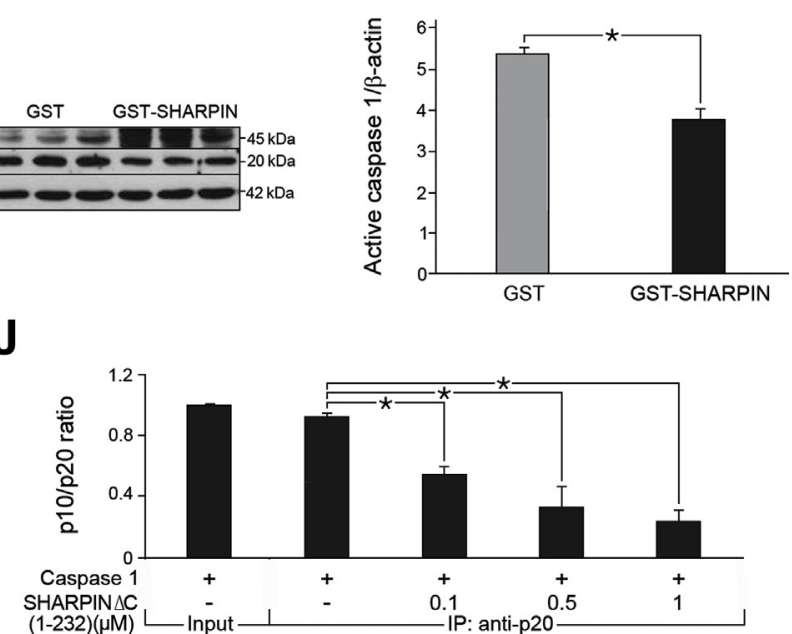

Figure 6 SHARPIN colocalizes with caspase 1 and influences caspase 1 activation. A-C: Colocalization of caspase 1 and SHARPIN in THP-1 cells unstimulated and stimulated with $1 \mu \mathrm{g} / \mathrm{mL}$ lipopolysaccharide (LPS) for 30 minutes and pulsed with $5 \mathrm{mmol} / \mathrm{L}$ ATP for 30 minutes. A: Confocal images for caspase 1 (green) and SHARPIN (red) show their colocalization after LPS + ATP treatment indicated by white arrows. B: Nuclei (blue) were stained with DAPI. The line scanning profiles, next to each confocal image, show the relative signal distribution for each fluorescent channel between the white arrows (SHARPIN in red and caspase 1 in green). C: Dot plots indicate the data set distribution and correlation index (ICorr). D and E: Influence of SHARPIN overexpression on levels of cleaved caspase 1 probed by immunoblot (D) and on caspase 1 activity shown by fluorescence-activated cell sorting analysis using FAM-YVAD-FMK FLICA (E) in THP-1 cells after stimulation with LPS + ATP. F: Influence of SHARPIN overexpression on levels of IL1 $\beta$ in culture media of THP-1 cells after stimulation with LPS + ATP. G and H: Inhibition of caspase 1 cleavage by SHARPIN at $30^{\circ} \mathrm{C}$ in LPS-stimulated THP-1 cells. Immunoblot for caspase 1 (G) and the densitometric quantification (H) of cleaved caspase 1 shown in G in THP-1 cells after incubation of THP-1 lysates with either glutathione S-transferase (GST)-SHARPIN or GST. I and J: Disruption of p20/p10 dimer of active caspase 1 by SHARPIN $\Delta C(1-232)$ after immunoprecipitation of caspase 1 p20. Immunoblot for caspase 1 p20 and p10 (I) and the densitometric quantification (J) of the p10/p20 ratio. Data are expressed as means $\pm \mathrm{SD}(\mathbf{C})$ or as means $\pm \mathrm{SEM}(\mathbf{H}$ and $\mathbf{J}) . n=3(\mathbf{A}, \mathbf{B}, \mathbf{D}-\mathbf{J}) ; n=$ at least 10 cells per condition $(\mathbf{C})$. ${ }^{\star} P<0.05($ unpaired two-tailed $t$-test). Scale bar $=10 \mu \mathrm{m}$. FAM-YVAD-FMK, carboxifluorescein-tyrosyl-valyl-alanyl-aspartyl-fluoromethylketone; IP, immunoprecipitation. 
and 11 (Figure 5B), in both control and LPS-treated mice, and this interaction was enhanced by LPS and could not be detected in the Sharpin-, Casp1-, and Casp11-deficient backgrounds (Figure 5, A and B). Interestingly, this complex did not include HOIL-1L and HOIP. Caspase 1 interacted with SHARPIN even in Casp $11^{-1-}$ mice, albeit to a lesser extent (Figure 5A). Figure 5C shows a slight increase in SHARPIN levels in LPS-treated mice compared to WT. However, after LPS treatment, SHARPIN is found to be much more abundant in complex with caspase 1 compared to WT (Figure 5A) due to increased levels of active caspase 1. Using GST-tagged full-length SHARPIN and the fragment containing the N-terminal 232 amino acid residues, SHARPIN $\Delta C$ (1-232), which lacks the nuclear protein localization protein 4 zinc finger (NZF) and ubiquitin-like (UBL) domains, ${ }^{15}$ we discovered that SHARPIN directly binds to human recombinant active caspase 1 and that the NZF and UBL domains of SHARPIN were dispensable for this binding (Figure 5D).

Next, we used microscale thermophoresis to determine the binding affinity of purified GST-SHARPIN to the recombinant active form of caspase 1 (Figure 5E). Active caspase 1 directly interacted with SHARPIN with dissociation constant $=$ $96 \pm 26 \mathrm{nmol} / \mathrm{L}$. No binding of GST to caspase 1 was identified (data not shown).

\section{SHARPIN Colocalizes with Caspase 1 and Inhibits Caspase 1 Activation in THP-1 Cells}

To confirm that SHARPIN and caspase 1 are found in complex we primed THP-1 cells, immune cells of human origin, with LPS and pulsed with ATP to activate the inflammasome and caspase $1^{11}$ and found colocalization of SHARPIN and caspase 1 (Figure 6, A-C). To determine SHARPIN effects on caspase 1 activation, we overexpressed SHARPIN in human monocytic THP-1 cells, stimulated with LPS + ATP, and showed that SHARPIN overexpression led to a decrease in the amount of secreted active p20 form of caspase 1 compared to control after LPS + ATP stimulation. In contrast, intracellular pro-caspase 1 remained unchanged (Figure 6D). Next, we utilized FAM-YVAD-FMK (FLICA), a fluorescent substrate peptide, which selectively binds to cleaved (active) caspase 1 enzyme. Under these conditions, SHARPINoverexpressing cells showed reduced FLICA (Figure 6E). The effect of SHARPIN on caspase 1 activation was further confirmed by its ability to block mature IL1 $\beta$ induction evoked by LPS + ATP stimulation (Figure $6 \mathrm{~F}$ ). Additionally, we found that SHARPIN inhibited the cleavage of pro-caspase 1 in vitro (Figure 6, G and H). Finally, we utilized affinity chromatography whereby active caspase 1 , consisting of p20/10 dimers, was bound to a column containing antibody against the p20 form. Increasing amounts of purified SHARPIN $\Delta \mathrm{C}$ (1-232), shown to bind active caspase 1 (Figure 5D), could efficiently prevent binding of the p20 form of active caspase 1 to the p10 form (Figure 6, I and J).

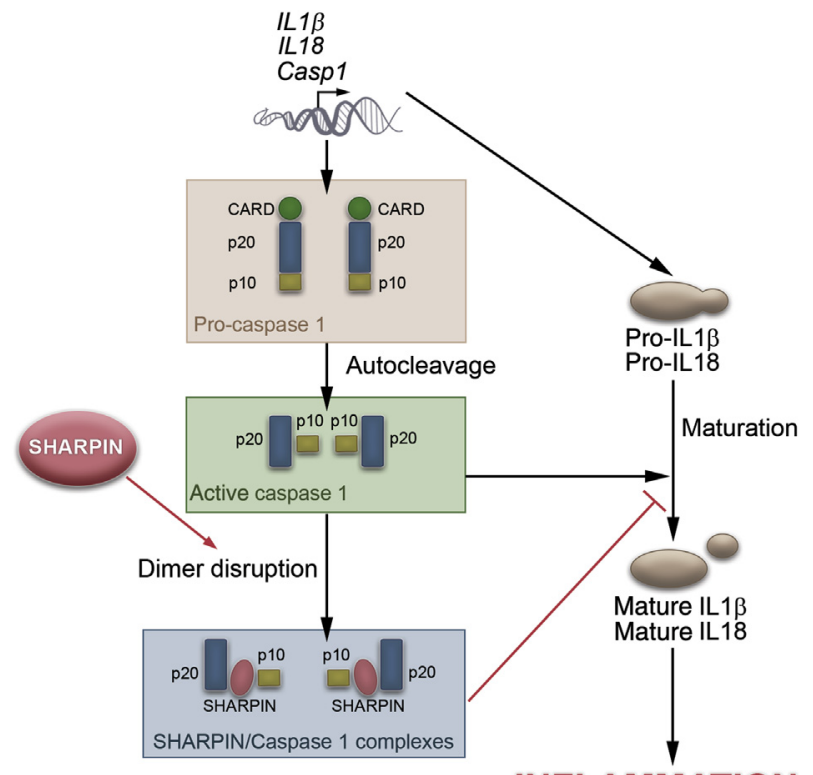

INFLAMMATION

Figure 7 SHARPIN-dependent inhibition of caspase 1 activation. SHARPIN directly interacts with the active p20p10 domain within pro caspase 1 and prevents its autocleavage to the active form. Second, SHARPIN binds active caspase 1 and destabilizes the p20/p10 dimers required for caspase 1 activity. Thus, SHARPIN-evoked p20/p10 dimer disruption decreases IL1 $\beta$ and IL18 maturation and consequently the inflammatory process. CARD, caspase recruitment domain.

\section{Discussion}

This is the first study showing SHARPIN as an endogenous inhibitor of caspase 1 activation. Of particular importance is our finding that SHARPIN blocks the p20/p10 dimer formation, the last and common step of caspase 1 activation. The multilayer caspase 1 activation is secured by various mechanisms. It is generally thought to occur after assembly of an inflammasome scaffold, with several inflammasomes existing, each activated in turn by specific stimuli ${ }^{11}$ and inflammatory caspase 11 , which can potentiate the inflammasome or directly cleave caspase $1 .{ }^{12,30}$ Following these pathways, pro-caspase 1 is cleaved into the active p10 and p20 subunits that assemble into a heterotetramer harboring two p20 and two p10 subunits. ${ }^{13,45}$ With this in mind, it is conceivable that blocking the p20/p10 dimer formation could be the most powerful pharmacologic approach, as the inhibition of any particular upstream inflammasome or caspase 11 will not completely block active caspase 1 . Moreover, by inhibiting one pathway, the other alternate pathways might increase their potential to activate caspase 1 due to compensatory effects.

Here we discovered that SHARPIN is found in a molecular complex with caspase 1 after co-immunoprecipitation in mouse lungs. Further, we show that through its N-terminal domain, SHARPIN directly binds to the active caspase 1 tetramer inhibiting the p20/p10 interaction and its activity, consequently preventing the release of mature cytokines. A 
working model of the proposed mechanism of action is provided in Figure 7.

Up to now, SHARPIN has been considered exclusively as a component of LUBAC. Interestingly, the SHARPINcaspase 1 complex does not contain the other LUBAC components HOIL-1L and HOIP, showing that the inhibitory role of SHARPIN is LUBAC independent. Furthermore, in septic human mononuclear cells, the negative correlation between SHARPIN and caspase 1 levels is autonomous of LUBAC.

Importantly, our study has unveiled a novel role for SHARPIN in the negative regulation of caspase 1 in LPSinduced endotoxemia. After either genetic or pharmacologic ablation of caspase 1, survival in $C p d m$ mice exposed to endotoxic shock is considerably increased. Thus, from a clinical translational perspective, our results indicate that natural (eg, SHARPIN) or synthetic caspase 1 inhibitors might provide a novel therapeutic approach for septic patients. Up to now only downstream effectors of caspase 1 have been targeted in sepsis (eg, by treatment with the natural IL1 receptor inhibitor anakinra), revealing quite disappointing clinical outcomes. ${ }^{8}$ As the effects of caspase 1 extend beyond processing IL1 $\beta$ and IL18, in addition to antibiotic therapy, it is conceivable that the inhibition of caspase 1 enzymatic activity could be a more effective therapeutic strategy. Indeed, we show that treatment with caspase 1 inhibitor not only decreases IL $1 \beta / 18$ levels but also prevents inflammatory death of splenic cells.

Our mechanistic and in vivo experimental findings are strongly underlined by clinical data. In circulating mononuclear cells from human septic patients, we found a low abundance of SHARPIN that negatively correlated with high levels of active caspase 1 . On the other hand, active caspase 1 levels positively correlated with HOIL-1L levels, consistent with the reported findings that HOIL-1L is required for inflammasome activation. ${ }^{44}$ These findings suggest a role for SHARPIN in controlling caspase 1 activation, opposite to and independent of the role played by other LUBAC components. To date, the only known case of SHARPIN deficiency in humans is the report of three patients with loss-of-function mutations in the HOILl gene. ${ }^{18}$ These patients display an autoinflammatory syndrome and experienced pyogenic bacterial infections, whereas cells isolated from them have lower levels of SHARPIN and HOIP proteins. ${ }^{18}$ Despite recent advances in medical science, effective new therapies for sepsis have not been forthcoming. ${ }^{46}$ Our findings suggest that using pharmacologic caspase 1 inhibitors, in particular SHARPIN-derived peptides blocking the p20/p10 dimer formation, could be beneficial in septic patients with low SHARPIN levels. We think that septic patients with a deficit in SHARPIN gene/ protein could be more efficiently treated by inhibiting caspase 1 than by other anti-inflammatory therapies. A number of caspase 1 inhibitors have been tested in humans. For example, the VX-765 inhibitor can effectively inhibit caspase 1 in cells from patients with familial cold autoinflammatory syndrome $\mathrm{s}^{47}$ and in a mouse model of epilepsy. ${ }^{48}$ In a Phase IIA trial, the administration of VX765 was found to be and well-tolerated. ${ }^{49}$

Our findings add new light to the understanding of the inflammatory $C p d m$ mouse phenotype. We demonstrate for the first time that genetic ablation of Caspl gene alone, but not of Casp11, rescues the Cpdm phenotype in various organs. Recently, higher levels of active caspases 1 and 11 were shown in the skin of unchallenged $\mathrm{Cpdm}$ mice, with concomitant ablation of caspases 1 and 11 reducing skin inflammation. ${ }^{50}$ In contrast to our findings, caspase 1/11-deficient $C p d m$ mice reported by Douglas et al ${ }^{50}$ still presented inflammatory skin lesions that developed before 14 weeks. Cpdm;Casp1/11 $1^{-/-}$ mice generated in our laboratory were free of any skin lesions at any age up to 1 year of continuous monitoring. In addition, we observed a pronounced reversion of the inflammatory lung phenotype in Cpdm mice lacking either Caspl or Caspl/11 genes. This apparent discrepancy can be partially explained by different experimental protocols, ours involving an extensive backcrossing of the mutant mice, ensuring uniform genetic background. Thus, in contrast to Douglas et al, ${ }^{50}$ we determined which of the two inflammatory caspases, caspase 1 or 11 , is the key player in the development of the Cpdm inflammatory phenotype.

Overall, we demonstrate that SHARPIN plays an essential role as a negative regulator of caspase 1 activation in inflammatory conditions, and propose novel therapeutic avenues for treating sepsis and other inflammatory conditions in which SHARPIN is decreased or absent.

\section{Acknowledgments}

We thank Riad Haceni for performing the IHC analysis, Anja Kirchhof for the help with genotyping and breeding of the mice, Drs. Vishva M. Dixit and Nobuhiko Kayagaki for kindly gifting mice deficient in caspase 1 and caspase 11, and Dr. Patrick Meybohm, Victoria Buderus, and Karin Pense for their help with patient enrollment.

M.-V.N., J.Z.-B., J.B., H.F., L.T.-H.H., C.P., and N.S. performed the experiments; J.L.-M. and J.M. provided research materials and analyzed the data; and M.-V.N., R.V.I., J.P., F.I., I.D., and L.S. designed the research and analyzed the data. All of the authors contributed to writing the manuscript and provided final approval of the submitted and published versions.

\section{Supplemental Data}

Supplemental material for this article can be found at http://dx.doi.org/10.1016/j.ajpath.2015.12.026.

\section{References}

1. Fink MP, Warren HS: Strategies to improve drug development for sepsis. Nat Rev Drug Discov 2014, 13:741-758 
2. Merx MW, Weber C: Sepsis and the heart. Circulation 2007, 116 : 793-802

3. Liu SF, Malik AB: NF-kappa B activation as a pathological mechanism of septic shock and inflammation. Am J Physiol Lung Cell Mol Physiol 2006, 290:L622-L645

4. Merline R, Moreth K, Beckmann J, Nastase MV, Zeng-Brouwers J, Tralhao JG, Lemarchand P, Pfeilschifter J, Schaefer RM, Iozzo RV, Schaefer L: Signaling by the matrix proteoglycan decorin controls inflammation and cancer through PDCD4 and MicroRNA-21. Sci Signal 2011, 4:ra75

5. Schaefer L, Babelova A, Kiss E, Hausser HJ, Baliova M, Krzyzankova M, Marsche G, Young MF, Mihalik D, Gotte M, Malle E, Schaefer RM, Grone HJ: The matrix component biglycan is proinflammatory and signals through Toll-like receptors 4 and 2 in macrophages. J Clin Invest 2005, 115:2223-2233

6. Ando H, Takamura T, Ota T, Nagai Y, Kobayashi K: Cerivastatin improves survival of mice with lipopolysaccharide-induced sepsis. J Pharmacol Exp Ther 2000, 294:1043-1046

7. Zhang X, Kimura Y, Fang C, Zhou L, Sfyroera G, Lambris JD, Wetsel RA, Miwa T, Song WC: Regulation of Toll-like receptormediated inflammatory response by complement in vivo. Blood 2007, 110:228-236

8. Opal SM, Fisher CJ Jr, Dhainaut JF, Vincent JL, Brase R, Lowry SF, Sadoff JC, Slotman GJ, Levy H, Balk RA, Shelly MP, Pribble JP, LaBrecque JF, Lookabaugh J, Donovan H, Dubin H, Baughman R, Norman J, DeMaria E, Matzel K, Abraham E, Seneff M: Confirmatory interleukin-1 receptor antagonist trial in severe sepsis: a phase III, randomized, double-blind, placebo-controlled, multicenter trial The Interleukin-1 Receptor Antagonist Sepsis Investigator Group. Crit Care Med 1997, 25:1115-1124

9. Vanden Berghe T, Demon D, Bogaert P, Vandendriessche B, Goethals A, Depuydt B, Vuylsteke M, Roelandt R, Van Wonterghem E, Vandenbroecke J, Choi SM, Meyer E, Krautwald S, Declercq W, Takahashi N, Cauwels A, Vandenabeele P: Simultaneous targeting of IL-1 and IL-18 is required for protection against inflammatory and septic shock. Am J Respir Crit Care Med 2014 189:282-291

10. Lamkanfi M, Dixit VM: Mechanisms and functions of inflammasomes. Cell 2014, 157:1013-1022

11. Schroder K, Tschopp J: The inflammasomes. Cell 2010, 140 821-832

12. Kayagaki N, Warming S, Lamkanfi M, Vande Walle L, Louie S, Dong J, Newton K, Qu Y, Liu J, Heldens S, Zhang J, Lee WP, RooseGirma M, Dixit VM: Non-canonical inflammasome activation targets caspase-11. Nature 2011, 479:117-121

13. Puri AW, Broz P, Shen A, Monack DM, Bogyo M: Caspase-1 activity is required to bypass macrophage apoptosis upon Salmonella infection. Nat Chem Biol 2012, 8:745-747

14. Corn JE, Vucic D: Ubiquitin in inflammation: the right linkage makes all the difference. Nat Struct Mol Biol 2014, 21:297-300

15. Ikeda F, Deribe YL, Skanland SS, Stieglitz B, Grabbe C, FranzWachtel M, van Wijk SJ, Goswami P, Nagy V, Terzic J, Tokunaga F Androulidaki A, Nakagawa T, Pasparakis M, Iwai K, Sundberg JP, Schaefer L, Rittinger K, Macek B, Dikic I: SHARPIN forms a linear ubiquitin ligase complex regulating NF-kappaB activity and apoptosis. Nature 2011, 471:637-641

16. Gerlach B, Cordier SM, Schmukle AC, Emmerich CH, Rieser E, Haas TL, Webb AI, Rickard JA, Anderton H, Wong WW, Nachbur U, Gangoda L, Warnken U, Purcell AW, Silke J, Walczak H: Linear ubiquitination prevents inflammation and regulates immune signalling. Nature 2011, 471:591-596

17. Tokunaga F, Nakagawa T, Nakahara M, Saeki Y, Taniguchi M, Sakata S, Tanaka K, Nakano H, Iwai K: SHARPIN is a component of the NF-kappaB-activating linear ubiquitin chain assembly complex. Nature 2011, 471:633-636

18. Boisson B, Laplantine E, Prando C, Giliani S, Israelsson E, Xu Z, Abhyankar A, Israel L, Trevejo-Nunez G, Bogunovic D, Cepika AM,
MacDuff D, Chrabieh M, Hubeau M, Bajolle F, Debre M, Mazzolari E, Vairo D, Agou F, Virgin HW, Bossuyt X, Rambaud C, Facchetti F, Bonnet D, Quartier P, Fournet JC, Pascual V, Chaussabel D, Notarangelo LD, Puel A, Israel A, Casanova JL, Picard C: Immunodeficiency, autoinflammation and amylopectinosis in humans with inherited HOIL-1 and LUBAC deficiency. Nat Immunol 2012, 13:1178-1186

19. Boisson B, Laplantine E, Dobbs K, Cobat A, Tarantino N, Hazen M, Lidov HG, Hopkins G, Du L, Belkadi A, Chrabieh M, Itan Y, Picard C, Fournet JC, Eibel H, Tsitsikov E, Pai SY, Abel L, Al-Herz W, Casanova JL, Israel A, Notarangelo LD: Human HOIP and LUBAC deficiency underlies autoinflammation, immunodeficiency, amylopectinosis, and lymphangiectasia. J Exp Med 2015, 212:939-951

20. HogenEsch H, Gijbels MJ, Offerman E, van Hooft J, van Bekkum DW, Zurcher C: A spontaneous mutation characterized by chronic proliferative dermatitis in C57BL mice. Am J Pathol 1993, 143:972-982

21. Wang Z, Potter CS, Sundberg JP, Hogenesch H: SHARPIN is a key regulator of immune and inflammatory responses. J Cell Mol Med 2012, 16:2271-2279

22. Seymour RE, Hasham MG, Cox GA, Shultz LD, Hogenesch H, Roopenian DC, Sundberg JP: Spontaneous mutations in the mouse Sharpin gene result in multiorgan inflammation, immune system dysregulation and dermatitis. Genes Immun 2007, 8:416-421

23. Potter CS, Wang Z, Silva KA, Kennedy VE, Stearns TM, Burzenski L, Shultz LD, Hogenesch H, Sundberg JP: Chronic Proliferative Dermatitis in Sharpin Null Mice: development of an Autoinflammatory Disease in the Absence of B and T Lymphocytes and IL4/IL13 Signaling. PLoS One 2014, 9:e85666

24. Rickard JA, Anderton H, Etemadi N, Nachbur U, Darding M, Peltzer N, Lalaoui N, Lawlor KE, Vanyai H, Hall C, Bankovacki A, Gangoda L, Wong WW, Corbin J, Huang C, Mocarski ES, Murphy JM, Alexander WS, Voss AK, Vaux DL, Kaiser WJ, Walczak H, Silke J: TNFR1-dependent cell death drives inflammation in Sharpin-deficient mice. Elife 2014, 3

25. Kumari S, Redouane Y, Lopez-Mosqueda J, Shiraishi R, Romanowska M, Lutzmayer S, Kuiper J, Martinez C, Dikic I, Pasparakis M, Ikeda F: Sharpin prevents skin inflammation by inhibiting TNFR1-induced keratinocyte apoptosis. Elife 2014, 3

26. Kahlenberg JM, Dubyak GR: Mechanisms of caspase- 1 activation by P2X7 receptor-mediated $\mathrm{K}+$ release. Am J Physiol Cell Physio 2004, 286:C1100-C1108

27. Laemmli UK: Cleavage of structural proteins during the assembly of the head of bacteriophage T4. Nature 1970, 227:680-685

28. Jaskolski F, Mulle C, Manzoni OJ: An automated method to quantify and visualize colocalized fluorescent signals. J Neurosci Methods 2005, 146:42-49

29. Jerabek-Willemsen M, Wienken CJ, Braun D, Baaske P, Duhr S: Molecular interaction studies using microscale thermophoresis. Assay Drug Dev Technol 2011, 9:342-353

30. Kang SJ, Wang S, Hara H, Peterson EP, Namura S, Amin-Hanjani S, Huang Z, Srinivasan A, Tomaselli KJ, Thornberry NA, Moskowitz MA, Yuan J: Dual role of caspase-11 in mediating activation of caspase- 1 and caspase-3 under pathological conditions. J Cell Biol 2000, 149:613-622

31. Kang SJ, Wang S, Kuida K, Yuan J: Distinct downstream pathways of caspase-11 in regulating apoptosis and cytokine maturation during septic shock response. Cell Death Differ 2002, 9:1115-1125

32. Rathinam VA, Vanaja SK, Waggoner L, Sokolovska A, Becker C, Stuart LM, Leong JM, Fitzgerald KA: TRIF licenses caspase-11dependent NLRP3 inflammasome activation by Gram-negative bacteria. Cell 2012, 150:606-619

33. Stehlik C: Multiple interleukin-1beta-converting enzymes contribute to inflammatory arthritis. Arthritis Rheum 2009, 60:3524-3530

34. Schonbeck U, Mach F, Libby P: Generation of biologically active IL1 beta by matrix metalloproteinases: a novel caspase-1-independent pathway of IL-1 beta processing. J Immunol 1998, 161:3340-3346 
35. Irmler M, Hertig S, MacDonald HR, Sadoul R, Becherer JD, Proudfoot A, Solari R, Tschopp J: Granzyme A is an interleukin 1 beta-converting enzyme. J Exp Med 1995, 181:1917-1922

36. Robertson SE, Young JD, Kitson S, Pitt A, Evans J, Roes J, Karaoglu D, Santora L, Ghayur T, Liew FY, Gracie JA, McInnes IB: Expression and alternative processing of IL-18 in human neutrophils. Eur J Immunol 2006, 36:722-731

37. Gijbels MJ, Zurcher C, Kraal G, Elliott GR, HogenEsch H, Schijff G, Savelkoul HF, Bruijnzeel PL: Pathogenesis of skin lesions in mice with chronic proliferative dermatitis (cpdm/cpdm). Am J Pathol 1996, 148:941-950

38. HogenEsch H, Janke S, Boggess D, Sundberg JP: Absence of Peyer's patches and abnormal lymphoid architecture in chronic proliferative dermatitis (cpdm/cpdm) mice. J Immunol 1999, 162:3890-3896

39. Iwai K: Linear polyubiquitin chains: a new modifier involved in NFkappaB activation and chronic inflammation, including dermatitis. Cell Cycle 2011, 10:3095-3104

40. Seymour R, Shirley BJ, Hogenesch H, Shultz LD, Sundberg JP: Loss of function of the mouse Sharpin gene results in Peyer's patch regression. PLoS One 2013, 8:e55224

41. Sieber S, Lange N, Kollmorgen G, Erhardt A, Quaas A, Gontarewicz A, Sass G, Tiegs G, Kreienkamp HJ: Sharpin contributes to TNFalpha dependent NFkappaB activation and anti-apoptotic signalling in hepatocytes. PLoS One 2012, 7:e29993

42. Greten FR, Arkan MC, Bollrath J, Hsu LC, Goode J, Miething C, Goktuna SI, Neuenhahn M, Fierer J, Paxian S, Van Rooijen N, Xu Y, O'Cain T, Jaffee BB, Busch DH, Duyster J, Schmid RM, Eckmann L, Karin M: NF-kappaB is a negative regulator of IL-1beta secretion as revealed by genetic and pharmacological inhibition of IKKbeta. Cell 2007, 130:918-931
43. Mathiak G, Grass G, Herzmann T, Luebke T, Zetina CC, Boehm SA, Bohlen H, Neville LF, Hoelscher AH: Caspase-1-inhibitor ac-YVAD-cmk reduces LPS-lethality in rats without affecting haematology or cytokine responses. Br J Pharmacol 2000, 131:383-386

44. Rodgers MA, Bowman JW, Fujita H, Orazio N, Shi M, Liang Q, Amatya R, Kelly TJ, Iwai K, Ting J, Jung JU: The linear ubiquitin assembly complex (LUBAC) is essential for NLRP3 inflammasome activation. J Exp Med 2014, 211:1333-1347

45. Elliott JM, Rouge L, Wiesmann C, Scheer JM: Crystal structure of procaspase-1 zymogen domain reveals insight into inflammatory caspase autoactivation. J Biol Chem 2009, 284:6546-6553

46. Angus DC, van der Poll T: Severe sepsis and septic shock. N Engl J Med 2013, 369:840-851

47. Stack JH, Beaumont K, Larsen PD, Straley KS, Henkel GW, Randle JC, Hoffman HM: IL-converting enzyme/caspase-1 inhibitor VX-765 blocks the hypersensitive response to an inflammatory stimulus in monocytes from familial cold autoinflammatory syndrome patients. J Immunol 2005, 175:2630-2634

48. Maroso M, Balosso S, Ravizza T, Iori V, Wright CI, French J, Vezzani A: Interleukin-1beta biosynthesis inhibition reduces acute seizures and drug resistant chronic epileptic activity in mice. Neurotherapeutics 2011, 8:304-315

49. Vezzani A, Balosso S, Maroso M, Zardoni D, Noe F, Ravizza T: ICE/caspase 1 inhibitors and IL-1beta receptor antagonists as potential therapeutics in epilepsy. Curr Opin Investig Drugs 2010, 11: $43-50$

50. Douglas T, Champagne C, Morizot A, Lapointe JM, Saleh M: The inflammatory caspases- 1 and -11 mediate the pathogenesis of dermatitis in Sharpin-deficient mice. J Immunol 2015, 195:2365-2373 